\title{
¿Cold Pool Characteristics of Tornadic Quasi-Linear Convective Systems and Other Convective Modes Observed during VORTEX-SE
}

\author{
Jessica M. MCDONALD ${ }^{\mathrm{a}}$ AND Christopher C. WeIss ${ }^{\mathrm{a}}$ \\ ${ }^{a}$ Department of Geosciences, Texas Tech University, Lubbock, Texas
}

(Manuscript received 13 July 2020, in final form 7 November 2020)

\begin{abstract}
Many numerical studies have focused on the importance of baroclinically generated vorticity at the edge of cold pools in supercellular tornadogenesis, and observational work has consistently found that strongly tornadic supercells have less dense, more buoyant cold pools than weakly or nontornadic supercells. However, there is a lack of observational studies that consider potential relationships between cold pool characteristics (e.g., density) and tornado production within linear systems, such as mesoscale convective system (MCS) or quasi-linear convective system (QLCS) events. This study presents two tornadic QLCS events that were observed during the Verification of the Origins of Rotation in Tornadoes ExperimentSoutheast (VORTEX-SE) field project in 2016 and 2017. Supercell and hybrid modes were also observed and compared to the observations from the linear systems. No obvious differences in the thermodynamic deficits of the tornadic and nontornadic samples were found, likely due to the weakness of the produced tornadoes $(\leq \mathrm{EF} 1)$ and the small tornadic sample size (five cold pools). Comparison across storm mode did find some differences, with QLCS cold pools producing larger virtual potential temperature and psuedoequivalent potential temperature deficits than those observed in supercells. More importantly, our findings suggest that, in a QLCS, the magnitude of density gradients along the leading edge of the cold pool may be related to tornadogenesis by virtue of the implied baroclinic vorticity generation.
\end{abstract}

SIGNIFICANCE STATEMENT: Despite lines of thunderstorms (rather than individual "supercell" storms) producing around $18 \%$ of all tornadoes in the United States, we are still learning how tornadoes develop within such storms. While past studies have found that the relative coldness of surface air produced within individual storm cells is related to tornado development, such a study has not yet been undertaken for lines of storms. Thus, in this study we explore relationships between the cold air within linear thunderstorms and tornadoes. Using surface observations collected in Alabama and Tennessee, we found that the relative rate at which the temperature decreased within these storms associates well with low-level rotation that could result in tornadoes. These results motivate further observational exploration of linear thunderstorms.

KEYWORDS: Baroclinic flows; Cold pools; Convective storms/systems; Tornadogenesis; Updrafts/downdrafts; Surface observations; Severe storms; Squall lines

\section{Introduction}

Horizontal baroclinic vorticity-vorticity generated by density (largely, temperature) gradients-is believed to play a role in the development of low-level vertical vorticity within supercell thunderstorms, based on supporting evidence provided by both numerical and observational studies. While environmental shear impacts the development of rotation in the midlevels of a supercell, different mechanisms, such as baroclinic torques, are widely considered to principally contribute to the development of low-level vertical vorticity (e.g., Davies-Jones 1982; Klemp and Rotunno 1983; Rotunno and Klemp 1985; Markowski et al. 2012; Dahl et al. 2014; Dahl 2015). Air parcels inbound to low-level mesocyclones can acquire horizontal vorticity along an outflow boundary ahead of negatively buoyant downdraft air and/or along internal

\footnotetext{
Denotes content that is immediately available upon publication as open access.
}

Corresponding author: Jessica M. McDonald, jessica.mcdonald@ ttu.edu boundaries in a supercell (e.g., the forward flank convergence boundary; Beck and Weiss 2013). Numerical studies have shown that baroclinic vorticity generation in supercells can reach magnitudes of $10^{-2} \mathrm{~s}^{-1}$ along the forward flank gust front (Klemp and Rotunno 1983; Rotunno and Klemp 1985) with weaker magnitudes of $10^{-4} \mathrm{~s}^{-1}$ along internal boundaries (Beck and Weiss 2013). The horizontal baroclinic vorticity can acquire a vertical component via vortex line slippage (DaviesJones and Brooks 1993; Dahl et al. 2014) during descent in the downdraft resulting in enhanced vertical vorticity which can be stretched by the updraft—a scenario that is conducive for tornadogenesis. Baroclinically generated vorticity dominates simulated vorticity budgets once cold pools become suitably established (e.g., Dahl et al. 2014; Dahl 2015; Markowski 2016), although frictionally generated vorticity can be the main vorticity source for near-surface parcels when surface drag is included in simulations (Schenkman et al. 2014; Roberts et al. 2016).

Observational studies in the Great Plains of the United States have also explored the role of baroclinic vorticity and buoyancy in tornadogenesis by observing the cold pools of supercells using mobile mesonet (e.g., Markowski et al. 2002; Shabbott and Markowski 2006; Grzych et al. 2007; Hirth et al. 2008; Skinner et al. 2011) or stationary platforms (e.g., 
"StickNets"; Skinner et al. 2011; Weiss et al. 2015). These studies observed that cold pools were less dense and less negatively buoyant within supercells that were strongly tornadic ( $\geq$ EF3) than those that were weakly tornadic or nontornadic. It is thought that the warmer cold pools result in stronger lowlevel updrafts and thus greater stretching of any near-surface vertical vorticity, which is favorable for tornado development. However, less negatively buoyant cold pools can also result in less production of streamwise (parallel to storm-relative flow) vorticity (Shabbott and Markowski 2006), implying that the higher buoyancy and increased low-level stretching associated with warmer cold pools can compensate the reduced vorticity generation. For nontornadic supercells, the higher density associated with stronger baroclinic regions will resist upward acceleration, reducing or eliminating low-level stretching (Markowski and Richardson 2014), thus making the baroclinically enhanced low-level vorticity less relevant.

Linear systems, such as quasi-linear convective systems (QLCS) and mesoscale convective systems (MCS), also rely on horizontal baroclinic vorticity generation to enhance vertical vorticity near the surface through a number of proposed mechanisms (Trapp and Weisman 2003; Wheatley and Trapp 2008; Atkins and St. Laurent 2009b; Flournoy and Coniglio 2019). Several numerical studies focused on mesovortex (MV) production, motivated by the potential of an MV to produce both tornadoes and damaging straight line winds when MV flow aligns with the rear inflow jet (RIJ; Smull and Houze 1987), enhancing already strong airflow (Weisman and Trapp 2003; Atkins and St. Laurent 2009a). A formative baroclinic mechanism described by Trapp and Weisman (2003) and supported by additional work (e.g., Wheatley and Trapp 2008; Parker et al. 2020) involves the downward tilting of baroclinically generated crosswise (perpendicular to storm-relative flow) horizontal vortex lines into a "U" shape by the downdraft, resulting in cyclonic and anticyclonic vortices in the low levels. The stretching of planetary vorticity is then necessary to break couplet symmetry and enhance the cyclonic member, resulting in potential cyclonic tornadogenesis. However, the Trapp and Weisman (2003) simulation had only crosswise vorticity in their storm environment, limiting the potential for more supercell-like vortexgenesis mechanisms. Wakimoto et al. (2006) also observed tilting of baroclinic horizontal vorticity by a downdraft using airborne radar; however, they argue the downdraft was driven by nearby updrafts rather than through latent cooling and precipitation loading. Atkins and St. Laurent (2009b) found different evolutions; in their simulations, baroclinic vorticity was tilted into the vertical by the updraft alone, and some of their simulated QLCS mesovortices were the result of mechanisms similar to those found in supercells (Markowski and Richardson 2009), a result also supported by the findings of Flournoy and Coniglio (2019).

Reorientation of baroclinic vorticity is only one of several potential mesovortexgenesis mechanisms. Other numerically and observationally identified sources of vorticity include ambient horizontal vorticity (Wheatley and Trapp 2008; Flournoy and Coniglio 2019), friction (Xu et al. 2015; Parker et al. 2020), the release of horizontal shearing instability (Wheatley and Trapp 2008; Conrad and Knupp 2019), and kinematic effects from a descending RIJ (Trapp and Weisman 2003; Atkins and St. Laurent 2009b; Xu et al. 2015; Flournoy and Coniglio 2019). Additionally, MV number and strength is positively related to the magnitude of low-level ambient shear (Weisman and Trapp 2003; Atkins and St. Laurent 2009a). Stronger vertical low-level shear normal to the cold pool edge can balance baroclinic vortex lines, leading to a stronger, more upright updraft (RKW theory; Rotunno et al. 1988) which can further stretch existing vertical vorticity. Increasing line-parallel shear can also promote the development of embedded supercells or supercell-like mechanisms, due to the potential for streamwise vorticity production. Many of the mechanisms listed above can act simultaneously within the same QLCS, as recently shown by Parker et al. (2020), though in some cases different mechanisms can seemingly counteract one another, as with frictionally and baroclinically generated vorticity.

While cold pools within supercells have been relatively well observed both temporally and spatially, such studies of surface cold pool observations within linear systems and their potential impact on mesovortexgenesis and tornadogenesis have not yet been undertaken, to the authors' knowledge. Engerer et al. (2008), Bryan and Parker (2010), and Hitchcock et al. (2019), observed temperature deficits within linear convective systems using mesonet or radiosonde observations, but did not discuss any relationship between these results and potential tornadogenesis. This lack of observational work leaves a gap in current understanding of how the magnitudes of-and variations within-cold pools of linear systems could impact mesovortexgenesis (and thus tornadogenesis), which should be improved upon considering that approximately $18 \%$ of all tornadoes are formed in linear systems (Trapp et al. 2005).

During the Verification of the Origins of Rotation in Tornadoes Experiment-Southeast (VORTEX-SE) Project, Texas Tech University used an array of StickNet observing platforms to observe the cold pools of all modes of southeastern United States convection (supercell, hybrid, and linear modes). The main purpose of this study is to begin filling the gap of observational studies of linear systems (QLCS or MCS events) by exploring any relationships between tornado potential and observed cold pool characteristics, namely, the strength of baroclinic zones and thermodynamic deficits. This study also compares cold pool deficits across all storm modes, and these deficits are explored to determine if they show differences between tornadic and nontornadic supercells or line segments.

\section{Methods}

\section{a. Data collection and quality control}

During VORTEX-SE, 16 solar-powered Texas Tech StickNet surface stations (Weiss and Schroeder 2008) were arranged across southern TN and northern AL during March and April for both 2016 and 2017 (Fig. 1). This array of StickNets is referred to as the "StesoNet." These $2.5 \mathrm{~m}$ AGL surface stations are capable of measuring wind speed and direction, temperature, relative humidity, and surface pressure at rates of up to $10 \mathrm{~Hz} .{ }^{1}$ For this study, the $10-\mathrm{Hz}$ data

\footnotetext{
${ }^{1}$ Further discussion of the StickNet sensor specifications (type A) can be found in Skinner et al. (2011).
} 


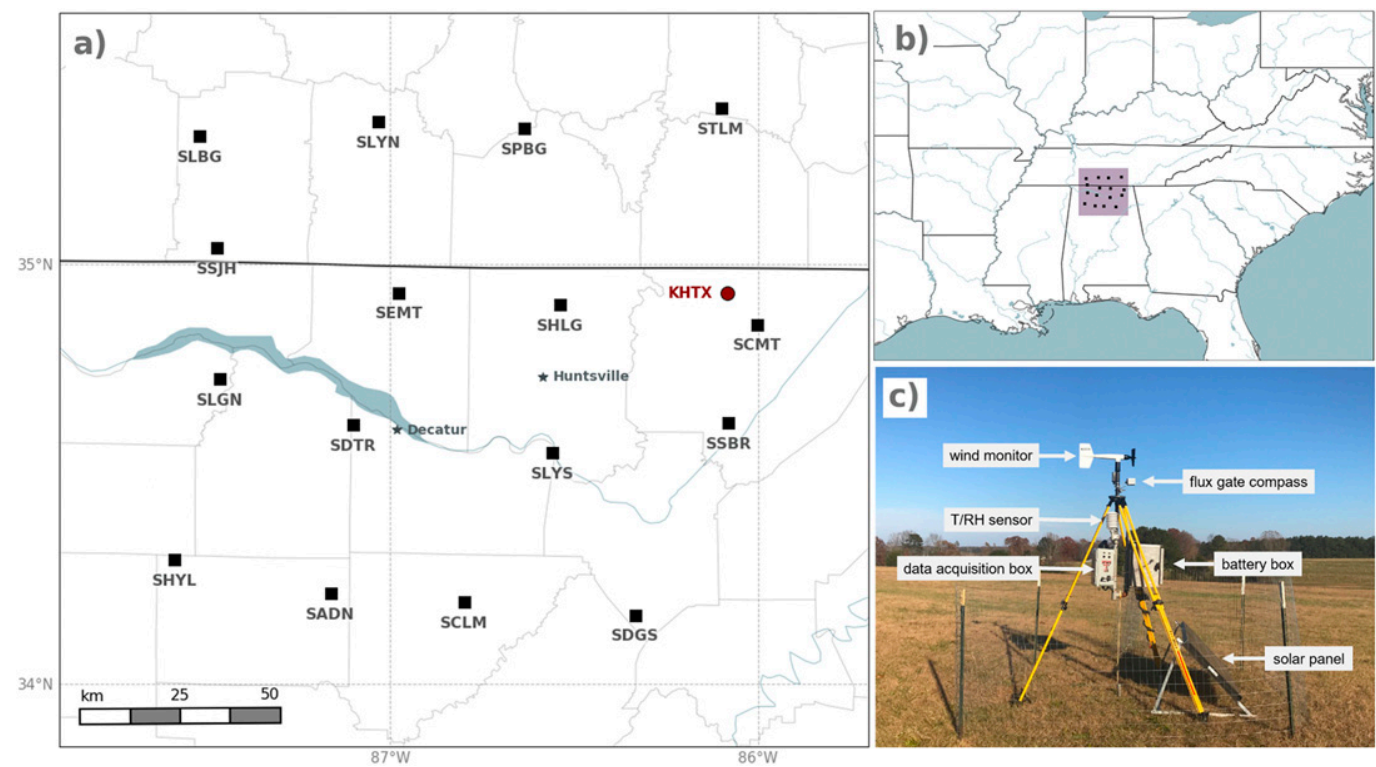

FIG. 1. The StesoNet domain during VORTEX-SE in 2016 and 2017, including the (a) zoomed and (b) regional view of StickNet locations, and (c) an overview of the components of a StickNet platform.

were discretely averaged to $1 \mathrm{~Hz}$. In addition to the StesoNet, eight more StickNets were reserved for rapid deployment ahead of ongoing convection to supplement the StesoNet observations. The different members of the StesoNet will be referred to by their location ID (e.g., "SCLM") while the finescale deployment StickNets ("Rapid StickNets") will be referred to by their ID number (e.g., "0218A").

While biases among the different StickNet instruments were calculated before and after each 2-month-long deployment, they are not included in this study due to their small magnitude and the focus on thermodynamic gradients which are relative to each StickNet. Additional quality control was performed through manual data inspection, and in several instances when a sensor was performing abnormally (e.g., rapid, large value changes) the extreme values were filtered or the data were not included in the results.

\section{b. Selection and classification of cases}

The goal of this study is to consider the cold pool characteristics of convection exhibiting storm-scale rotation. To determine if a thunderstorm had sufficient rotation to be included in the analyses, inferred vorticity fields were calculated from the lowest velocity scan from the nearest WSR-88D (typically KHTX), using the following equation:

$$
\zeta_{i}=\frac{2}{r \sin (\phi)} \frac{\partial V_{r}}{\partial \theta}
$$

where $\zeta_{i}$ is the inferred vertical vorticity (assuming solid body rotation), $r$ is the radial distance from the radar, $\phi$ is the zenith angle, $V_{r}$ is the radial velocity field, and $\theta$ is the azimuth. If an identified velocity couplet within a thunderstorm had inferred vertical vorticity that exceeded $0.01 \mathrm{~s}^{-1}$, the storm producing that couplet was considered to be rotating. No duration or size criteria were applied to the vorticity objects; the process of determining threshold exceedance was somewhat subjective due to varying data quality related to storm orientation and/or distance from the radar. A StickNet measurement was included in this study and designated as "near rotation" or "near tornado" if it contained observations of a thunderstorm that produced rotation or a tornado within $15 \mathrm{~km}$ of the StickNet, respectively. The tornado tracks were verified using the Damage Assessment Toolkit provided by the National Weather Service (NWS), the Storm Events Database, and event reports from the NWS offices themselves. A radius of $15 \mathrm{~km}$ was chosen as it subjectively appeared to be a reasonable approximation of the horizontal cold pool extent of individual cells and allowed for a suitably large dataset of nine events (Table 1) with 39 observations of rotating storms or linear segments (Table 2). The 15-km distance from

TABLE 1. VORTEX-SE event dates, mode of convection, and number of observations that met the designated criteria for "near tornado" or "near rotation."

\begin{tabular}{lcccc}
\hline \hline \multicolumn{1}{c}{ Date } & Mode & $\begin{array}{c}\text { No. of } \\
\text { obs near } \\
\text { tornado }\end{array}$ & $\begin{array}{c}\text { No. of } \\
\text { obs near } \\
\text { rotation }\end{array}$ & $\begin{array}{c}\text { VORTEX- } \\
\text { SE IOP }\end{array}$ \\
\hline 31 Mar 2016 & Supercell & - & 7 & IOP3 \\
30 Apr 2016 & Supercell & - & 1 & IOP4C \\
1 Mar 2017 & Supercell & - & 3 & - \\
10 Mar 2017 & Linear & 2 & 1 & UFO-1 \\
21 Mar 2017 & Linear & - & 1 & - \\
25 Mar 2017 & Hybrid & - & 4 & IOP1A \\
27 Mar 2017 & Hybrid & - & 5 & IOP1B \\
22 Apr 2017 & Supercell & 2 & 2 & IOP3.5B \\
30 Apr 2017 & Linear & 1 & 10 & IOP4C \\
\hline
\end{tabular}


TABLE 2. Summary of the methods applied to each StickNet intercept discussed in this study. These include TOA, storm motion, the angle used for the $\theta_{v}$ gradient, and any modifications to the methods as discussed in the text. The modifications include changes to the basestate starting distance (BS: starting distance; $\mathrm{km}$ ) or TOA time (TOA: minutes changed). StickNet IDs with an asterisk (*) were only used in case studies for intraevent comparison. The $\nabla \theta_{v}$ angles that are marked with a dagger $(\dagger)$ were obtained using velocity data, rather than reflectivity.

\begin{tabular}{|c|c|c|c|c|c|}
\hline Date & StickNet ID & TOA (UTC) & Storm motion: $u, v\left(\mathrm{~m} \mathrm{~s}^{-1}\right)$ & $\nabla \theta_{v}$ angle $\left({ }^{\circ}\right)$ & Modifications \\
\hline 31 Mar 2016 & 0220A & 2216 & $15.4,3.9$ & -6.0 & \\
\hline 31 Mar 2016 & $0222 \mathrm{~A}$ & 2216 & $15.4,3.9$ & -30.0 & BS: 10.5 \\
\hline 31 Mar 2016 & 0221A & 2228 & $19.2,7.7$ & -19.0 & \\
\hline 31 Mar 2016 & 0217A & 2232 & $15.0,3.8$ & -40.0 & BS: 10.6 \\
\hline 31 Mar 2016 & SSJH & 2249 & $17.8,3.6$ & -60.0 & \\
\hline 31 Mar 2016 & 0218A & 2249 & $17.8,3.6$ & -22.0 & \\
\hline 31 Mar 2016 & SSJH & 2307 & $16.6,3.3$ & -30.0 & BS: 32.2 \\
\hline 30 Apr 2016 & SDTR & 2142 & $9.6,16.0$ & 32.0 & TOA: -1.0 \\
\hline 1 Mar 2017 & SDTR & 1903 & $29.2,7.3$ & -55.0 & \\
\hline 1 Mar 2017 & $0103 \mathrm{~A}$ & 1945 & $26.5,7.6$ & -11.0 & \\
\hline 1 Mar 2017 & 0109A & 1950 & $25.6,7.3$ & 15.0 & \\
\hline 10 Mar 2017 & SLBG* & 0507 & $24.1,-8.0$ & -68.0 & \\
\hline 10 Mar 2017 & SLYN & 0525 & $23.6,-7.9$ & -51.0 & \\
\hline 10 Mar 2017 & SSJH* & 0535 & $20.8,-5.2$ & -61.0 & TOA: -1.0 \\
\hline 10 Mar 2017 & SPBG & 0541 & $21.3,-10.7$ & -60.0 & \\
\hline 10 Mar 2017 & SEMT* & 0559 & $21.4,-8.0$ & -60.0 & \\
\hline 10 Mar 2017 & STLM & 0609 & $24.0,-5.3$ & -56.0 & \\
\hline 10 Mar 2017 & SHLG* & 0615 & $24.0,-5.3$ & -26.0 & \\
\hline 10 Mar 2017 & SLGN* & 0620 & $18.8,-5.4$ & -68.0 & \\
\hline 10 Mar 2017 & SDTR* & 0627 & $22.2,-5.6$ & -28.0 & \\
\hline 10 Mar 2017 & SCMT* & 0636 & $25.1,-8.4$ & -54.0 & \\
\hline 10 Mar 2017 & SLYS* & 0645 & $24.5,-2.7$ & -56.0 & \\
\hline 10 Mar 2017 & SSBR* & 0650 & $24.5,-5.4$ & -57.0 & \\
\hline 10 Mar 2017 & SHYL* & 0721 & $21.5,-6.1$ & -66.0 & \\
\hline 10 Mar 2017 & SCLM* & 0722 & $21.5,-3.1$ & -70.0 & \\
\hline 10 Mar 2017 & SDGS* & 0730 & $23.8,-6.0$ & -37.0 & TOA: -1.0 \\
\hline 21 Mar 2017 & SLYN & 2112 & $15.7,-3.1$ & -38.0 & \\
\hline 25 Mar 2017 & SDTR & 1830 & $7.4,18.5$ & 20.0 & \\
\hline 25 Mar 2017 & SEMT & 1858 & $7.1,17.8$ & 32.0 & \\
\hline 25 Mar 2017 & SPBG & 1946 & $7.0,20.9$ & $26.0^{\dagger}$ & TOA: 7.0 \\
\hline 27 Mar 2017 & SEMT & 2053 & $13.5,6.8$ & $-38.0^{\dagger}$ & \\
\hline 27 Mar 2017 & $0222 \mathrm{~A}$ & 2109 & $17.3,6.9$ & -40.0 & BS: 8.5 \\
\hline 27 Mar 2017 & SDTR & 2120 & $16.2,6.5$ & -41.0 & \\
\hline 27 Mar 2017 & SHLG & 2146 & $17.1,10.2$ & $-42.0^{\dagger}$ & \\
\hline 28 Mar 2017 & SDGS & 0000 & $13.5,-3.4$ & -28.0 & TOA: -4.0 \\
\hline 22 Apr 2017 & SHYL & 2126 & $16.3,-2.7$ & -50.0 & \\
\hline 22 Apr 2017 & SHLG & 2200 & $18.1,-2.6$ & -42.0 & \\
\hline 22 Apr 2017 & SADN & 2225 & $12.7,-2.5$ & -44.0 & \\
\hline 22 Apr 2017 & SCMT & 2249 & $18.9,-2.7$ & 36.0 & \\
\hline 22 Apr 2017 & SCLM & 2310 & $14.4,2.9$ & -9.0 & \\
\hline 30 Apr 2017 & SHYL & 1808 & $11.4,19.0$ & 32.0 & \\
\hline 30 Apr 2017 & SLBG* & 1828 & $11.4,22.8$ & -10.0 & \\
\hline 30 Apr 2017 & 0220A & 1832 & $10.6,17.6$ & 35.0 & \\
\hline 30 Apr 2017 & SSJH* & 1833 & $10.6,17.6$ & -1.0 & \\
\hline 30 Apr 2017 & 0222A & 1836 & $14.0,14.0$ & 14.0 & \\
\hline 30 Apr 2017 & SLGN & 1836 & $10.5,17.5$ & 8.0 & \\
\hline 30 Apr 2017 & 0221A & 1837 & $14.0,14.0$ & 30.0 & \\
\hline 30 Apr 2017 & $0218 \mathrm{~A}$ & 1838 & $14.0,14.0$ & -14.0 & \\
\hline 30 Apr 2017 & $0224 \mathrm{~A} *$ & 1846 & $14.4,18.1$ & 17.0 & \\
\hline 30 Apr 2017 & SADN & 1847 & $10.8,18.1$ & 32.0 & TOA: 1.0 \\
\hline 30 Apr 2017 & 0219A* & 1851 & $10.5,17.5$ & 6.0 & \\
\hline 30 Apr 2017 & SDTR & 1856 & $10.5,21.1$ & 5.0 & \\
\hline 30 Apr 2017 & SCLM & 1908 & $13.1,16.3$ & 27.0 & \\
\hline 30 Apr 2017 & SEMT & 1921 & $12.4,15.5$ & 20.0 & \\
\hline
\end{tabular}


TABLE 2. (Continued)

\begin{tabular}{|c|c|c|c|c|c|}
\hline Date & StickNet ID & TOA (UTC) & Storm motion: $u, v\left(\mathrm{~m} \mathrm{~s}^{-1}\right)$ & $\nabla \theta_{v}$ angle $\left({ }^{\circ}\right)$ & Modifications \\
\hline 30 Apr 2017 & SLYN* & 1929 & $12.4,18.6$ & -1.0 & \\
\hline 30 Apr 2017 & SLYS & 1943 & $10.7,16.0$ & 29.0 & TOA: 1.0 \\
\hline 30 Apr 2017 & SHLG* & 1955 & $11.0,16.5$ & 19.0 & \\
\hline 30 Apr 2017 & SDGS* & 2001 & $12.3,12.3$ & 2.0 & \\
\hline 30 Apr 2017 & SPBG* & 2001 & $12.3,17.2$ & 36.0 & \\
\hline 30 Apr 2017 & SSBR* & 2029 & $12.3,9.8$ & 10.0 & \\
\hline 30 Apr 2017 & SCMT* & 2042 & $10.1,17.6$ & 25.0 & \\
\hline 30 Apr 2017 & STLM* & 2047 & $12.6,17.6$ & 7.0 & \\
\hline
\end{tabular}

rotation is within the horizontal distances that other observational studies, such as Shabbott and Markowski (2006) and Weiss et al. (2015), used in their analyses.

The events included in this study have a variety of storm modes, including linear convective systems (linear mode), relatively discrete supercells (supercell mode), and a hybrid mode of embedded supercells (hybrid mode). To determine event mode, the lowest available reflectivity data $\left(0.5^{\circ}\right.$ elevation) were subjectively studied for convective patterns. An event that did not have any breaks in high reflectivity values (i.e., it appeared that the cold pool was unbroken along the length of convection) was classified as linear, including both MCS and QLCS events. The hybrid-mode designation was given to events characterized by a broken convective line containing embedded supercells, where other embedded cells were of equal size and reflectivity intensity. The supercell designation was applied to events with supercells that either had an inflow region clear of other convection or the supercell was part of a convective complex but was the dominant cell (i.e., had the largest reflectivity values and/or covered the largest area). Separating the events by mode allows for comparison of results between and within the categories.

\section{c. Cold pool characterization}

The variables most commonly used to quantify the magnitude of cold pools are virtual potential temperature $\left(\theta_{v}\right)$, density potential temperature $\left(\theta_{\rho}\right)$, and pseudoequivalent potential temperature $\left(\theta_{\text {ep }}\right.$, hereafter called $\left.\theta_{e}\right)$. Since $\theta_{\rho}$ requires a quantitative measurement of liquid water content (e.g., derived from finescale mobile radar reflectivity data), this variable will not be used in this study. Therefore, baroclinic regions discussed in the results may be weaker than "truth" since $\theta_{v}$ underestimates negative buoyancy in regions of precipitation $^{2}$ (Shabbott and Markowski 2006; Hirth et al. 2008) and gradients of virtual temperature and liquid water content are often very close to antiparallel.

The formulas used for $\theta_{v}$ and $\theta_{e}$ are those derived in Bolton (1980):

$$
\theta_{v}=\theta(1+0.61 w)
$$

\footnotetext{
${ }^{2}$ Shabbott and Markowski (2006) demonstrated that when $\theta=$ $300 \mathrm{~K}, \theta_{v}$ will be $6 \mathrm{~K}$ warmer than $\theta_{\rho}$ if reflectivity is $65 \mathrm{dBZ}$ or higher, which is significant. However, the error is less than $1 \mathrm{~K}$ for reflectivities lower than $50 \mathrm{dBZ}$.
}

and

$$
\theta_{e}=\theta_{\mathrm{LCL}} \exp \left[\frac{3036.0}{T_{\mathrm{LCL}}} w(1.0+0.448 w)\right],
$$

where $w$ is the mixing ratio $\left(\mathrm{kg} \mathrm{kg}^{-1}\right), \theta$ is the potential temperature, and $\theta_{\mathrm{LCL}}$ and $T_{\mathrm{LCL}}$ are the estimated potential temperature and temperature at the LCL, respectively. The equations for these variables can also be found in Bolton (1980).

To quantify the effects of the StickNet temperature and relative humidity sensor errors (see Skinner et al. 2011) in Eqs. (2) and (3), the errors of $2 \% \mathrm{RH}$ and $0.3 \mathrm{~K}$ were applied to the variables used in the equations and compared to "truth." This analysis found that for the typical VORTEX-SE temperatures (around $25^{\circ} \mathrm{C}$ ) at high relative humidity (conditions near and in the cold pool are usually near saturation), the combined temperature and $\mathrm{RH}$ errors lead to, at most, a $2.6 \mathrm{~K}$ error in $\theta_{e}$ and a $0.4 \mathrm{~K}$ error in $\theta_{v}$.

\section{1) TIME OF ARRIVAL}

To calculate the base state, the cold pool time of arrival (TOA) is required. No consistent method for determining the TOA has been introduced in past convective cold pool studies; cold pool edges have been identified using wind shifts (Engerer et al. 2008) or subjectively (e.g., Hirth et al. 2008; Skinner et al. 2011). Since not all of the cold pools in the VORTEX-SE events had clear wind shifts, analysis of 1-min-averaged $\theta_{v}$ time series data was employed instead. An algorithm was used to inspect a small subset of data surrounding each cold pool passage, to determine when a 1-min decrease in $\theta_{v}$ exceeded a set threshold value (typically $0.3 \mathrm{~K}$ ). ${ }^{3}$ The time at the beginning of that 1-min period was then used as the TOA. Each TOA placement was inspected and, of the 39 observations, five TOA times $(13 \%)$ were manually adjusted (Table 2).

\section{2) BAse STATE}

In past studies, determining environmental "base-state" conditions, which are the conditions that a storm is perturbing, often involved placing a single observing station in the inflow of a convective cell of interest (e.g., Hirth et al. 2008; Weiss

\footnotetext{
${ }^{3}$ The threshold value of $0.3 \mathrm{~K}$ was subjectively altered for three events (31 Mar 2016 used 0.15 K, 10 Mar 2017 used 0.27 K, and 21 Mar 2017 used $0.4 \mathrm{~K}$ ), owing to unique inflow environments and cold pool presentations.
} 
a)

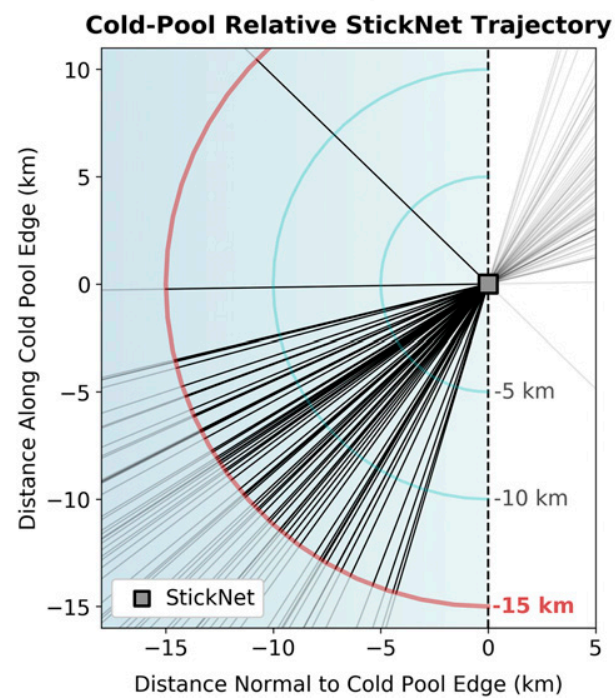

b)

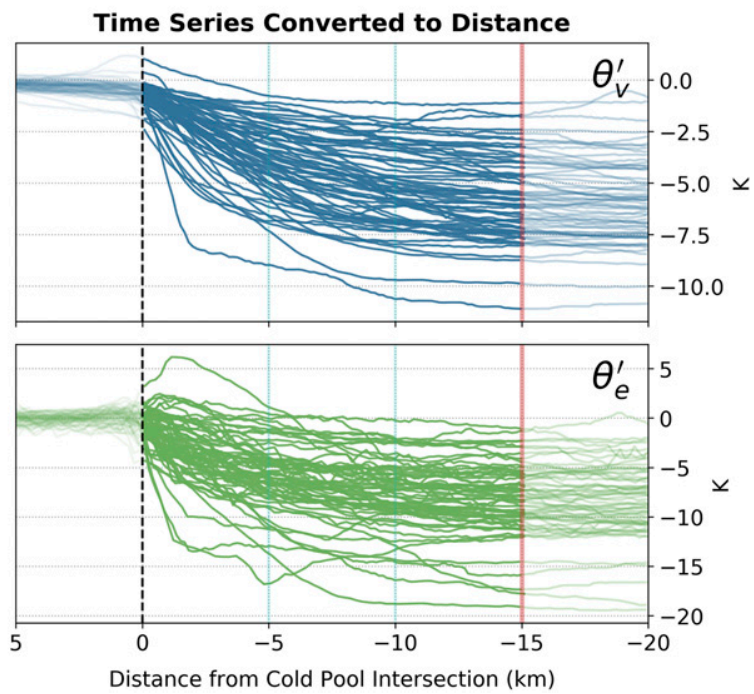

FIG. 2. Visualization of the method for determining cold pool deficits, for all cold pool observations listed in Table 2. (a) All the trajectories (black lines) that the StickNets traced through a cold pool (blue shading), given the storm-motion vectors and estimated cold pool orientations. The StickNet (gray square) represents the arbitrary point of cold pool intersection. (b) Time series of $\theta_{v}$ (blue lines, $\mathrm{K}$ ) and $\theta_{e}$ (green lines, $\mathrm{K}$ ) perturbations converted to distance based on storm velocity. In both (a) and (b), the dashed line denotes the cold pool edge, and the red line marks the 15-km StickNet-relative distance. Negative distances are within the cold pool.

et al. 2015) or making a spatial average of conditions ahead of a cell (e.g., Markowski et al. 2002; Skinner et al. 2011). However, these techniques cannot be used in this study due to the spatial distance (typically $40 \mathrm{~km}$ ) between the StickNets that comprise the StesoNet. The environment cannot be assumed homogeneous over that scale, so each StickNet that experiences a cold pool must have its own base-state conditions. The need for a unique base state for each StickNet is especially important when considering the expansive cold pools of linear modes, which can extend the length of the StesoNet domain. The base state is calculated by converting time to distance using the estimated thunderstorm speed and averaging the data collected between 10 and $15 \mathrm{~km}$ ahead of the point of cold pool intersection, a region expected to be under most or all anvil shading. Events that occur during daylight hours can have appreciable cooling (several degrees Celsius) beneath the anvil (Dowell and Bluestein 1997; Markowski et al. 1998), which is deemed in this study to be most representative of the nearinflow environment. If the selected data were affected by preceding heavy convection (i.e., the variables were rapidly changing) or if a StickNet was deployed too close to the cold pool edge (an issue for the rapid StickNets), the next closest 5$\mathrm{km}$ length ahead of the cold pool edge (e.g., 12.5 to $7.5 \mathrm{~km}$ ) was used for the base-state calculation instead (Table 2). While subjective, this technique provides a consistent method to determine the appropriate base state given the broad distribution of the StesoNet. However, caution should be taken when comparing the deficits calculated using this method to those of other studies that derived base-state values differently.

To limit subjectivity in estimating storm motion, an algorithm was used to determine the storm motion from radar reflectivity [similar to the method used by Shabbott and Markowski (2006)]. For each StickNet, the lowest elevation radar data from two consecutive scans (near TOA for each StickNet/event) were interpolated to a 1-km grid using the gridding function provided by the Py-ART Python package (Helmus and Collis 2016) and subset to a $40-\mathrm{km}$ box centered on the StickNet of interest. The earlier of the two reflectivity scans was then shifted until the mean square error between it and the later reflectivity scan was minimized. The storm motion vector could then be determined from the magnitude and sign of this shift, divided by the time between scans.

\section{3) COLD POOL DEFICITS}

Calculating the $\theta_{v}$ and $\theta_{e}$ deficits of each sampled cold pool is one of the main objectives of this study. Past observational studies have either calculated the deficits for large swaths of the cold pool (e.g., Shabbott and Markowski 2006; Weiss et al. 2015), within set distances of specific features such as the lowlevel mesocyclone or a tornado (Markowski et al. 2002), or within a certain amount of time since cold pool arrival (Engerer et al. 2008). In an effort to make these results comparable to other studies, the $\theta_{v}$ and $\theta_{e}$ deficits were calculated by subtracting the base state from the corresponding minimum value found within $15 \mathrm{~km}$ of the cold pool arrival at a StickNet. The 15-km distance was determined using the estimated storm speed. As the direction of storm motion was not considered, projections of this $15-\mathrm{km}$ distance yielded distances as small as $5 \mathrm{~km}$ normal to the cold pool edge, depending on the storm motion vector (Fig. 2a). However, almost all of the temperature change within each cold pool occurred within the $15-\mathrm{km}$ 
StickNet-relative distance (Fig. 2b), so no corrections to this method were applied. For calculations that rely on cold pool edge-relative position (i.e., $\theta_{v}$ gradients, see section 4 ), additional steps were taken to accurately project gradients into the edge-normal direction.

As with similar previous studies that focus on cold pool deficits (e.g., Markowski et al. 2002; Shabbott and Markowski 2006; Weiss et al. 2015), it is important to remember that variations in the base state across samples, at the surface and aloft, also affect the buoyancy of a lifted parcel coming from the cold pool. Therefore, while $\theta_{v}$ and $\theta_{e}$ deficit magnitudes are helpful in partially determining characteristic shifts in buoyancy across cases (or, to a greater extent, different segments of the same case), they cannot solely explain these shifts.

\section{4) $\theta_{v}$ GRADIENT}

This study considers observed temporal $\theta_{v}$ gradients to be baroclinic regions, and uses their magnitude as a proxy for potential baroclinic vorticity generation. Stronger gradients can lead to larger baroclinic vorticity generation, assuming that parcels reside within the baroclinic zone for an adequate period of time. To get an accurate point estimate of the $\theta_{v}$ gradient, the measurements across the cold pool edge need to be parallel to the $\theta_{v}$ gradient. Unless the storm motion vector is perfectly normal to the cold pool edge, the $\theta_{v}$ gradient recorded by a StickNet is a projection of the actual gradient (Fig. 3). Since the actual orientation of the $\theta_{v}$ gradient is unknown, the reflectivity gradient was used as a proxy for the $\theta_{v}$ gradient. The reflectivity gradient angle was found by visually estimating the orientation angle of the sharpest reflectivity gradient. For three observations of embedded supercells with less obvious gradient edges, gust front features on velocity images were used to infer the $\theta_{v}$ gradient (Table 2).

Once the storm motion vector and $\theta_{v}$ gradient vector estimates were found, StickNet-relative distances could be converted to cold pool edge-relative distances by using the simple equation:

$$
n=d \cos \left(\phi_{c}\right) \text {, }
$$

where $n$ is the distance normal to the cold pool edge, $d$ is the StickNet-relative distance, and $\phi_{c}$ is the difference in angle between the storm motion vector and $\theta_{v}$ gradient vector (Fig. 3). Using $n$, a $1-\mathrm{km}$ rolling distance was used to find the maximum $1-\mathrm{km}$ change in $\theta_{v}$, starting $2 \mathrm{~km}$ ahead of the cold pool edge and ending $10 \mathrm{~km}$ into the cold pool. ${ }^{4}$ The largest $\theta_{v}$ change found was used to represent the maximum baroclinity found near the cold pool edge, and is referred to as $d \theta_{v} / d n$. Different rolling distances were also tested $(0.5$, 1.5 , and $2 \mathrm{~km}$ ) and all produced different gradient magnitudes but with nearly identical relative patterns. This method allows for comparison of estimated cold pool baroclinity from all observed storms, regardless of storm speed or orientation.

\footnotetext{
${ }^{4}$ One StickNet time series from 31 Mar 2016 (SSJH) could only be searched for maximum baroclinity within $5 \mathrm{~km}$ of the cold pool edge, rather than $10 \mathrm{~km}$, due to another cold pool arrival.
}

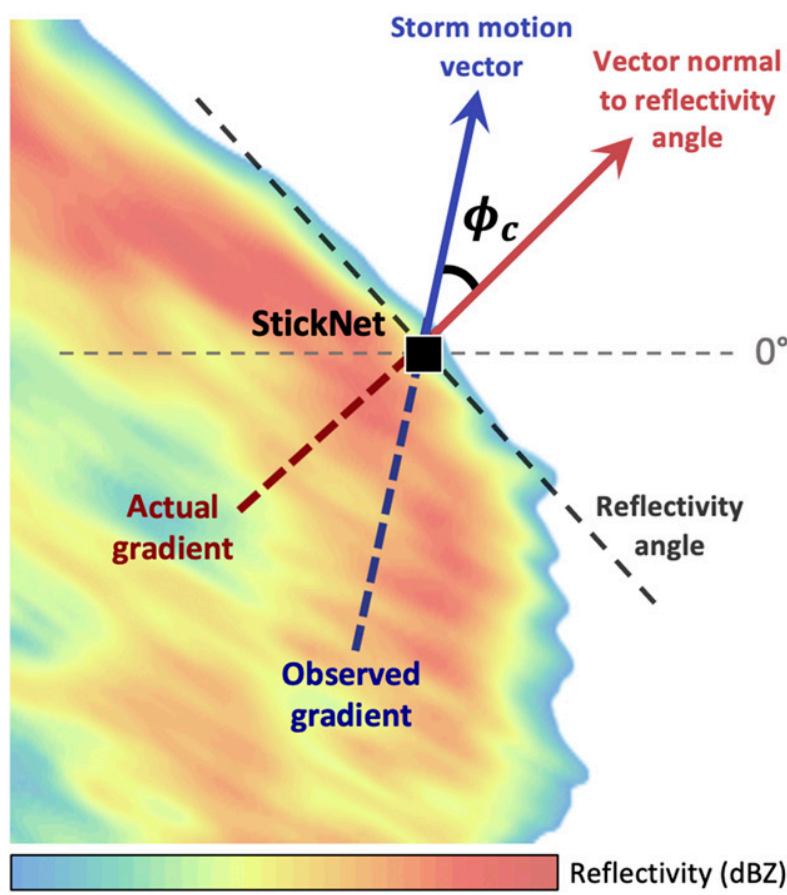

FIG. 3. Visualization of the correction angle $\left(\phi_{c}\right)$, where the shading represents radar reflectivity, and the black square is a StickNet.

Determining the reflectivity gradient is subjective, resulting in errors in the gradient calculation that cannot be fully quantified. However, for one of the main QLCS events, 30 April 2017, the results from this method were compared to a time-to-space analysis calculated from a finescale deployment, and it appeared to adequately capture variations in the gradients along the cold pool edge (not shown). Additionally, various sensitivity tests to potential errors in the reflectivity gradient (estimated to be up to $\pm 10^{\circ}$ ) and storm motion calculations (estimated to be up to $\pm 5 \mathrm{~ms}^{-1}$ in both $u$ and $v$ components) were undertaken. It was found that the inclusion of these errors did not significantly alter the results from what is presented here. Therefore, the authors feel confident that this method is sufficiently accurate to yield reasonable estimates of edge-normal density gradients.

\section{Results}

Of the nine events that met the designated criteria, three of them produced tornadoes. Two of the tornadic cases were from linear events, and the other was a supercell case. Due to the lack of discussion regarding the observations of cold pools of tornadic linear systems in past literature, the results will focus mainly on the linear systems that produced tornadoes, and supplement these results with those found in the supercell and hybrid cases.

While numerical and observational studies have not specifically examined the source of vorticity directly ingested by mesovortex tornadoes, radar studies have found that mesovortices that produce tornadoes tend to be stronger and longer 
10 March 2017

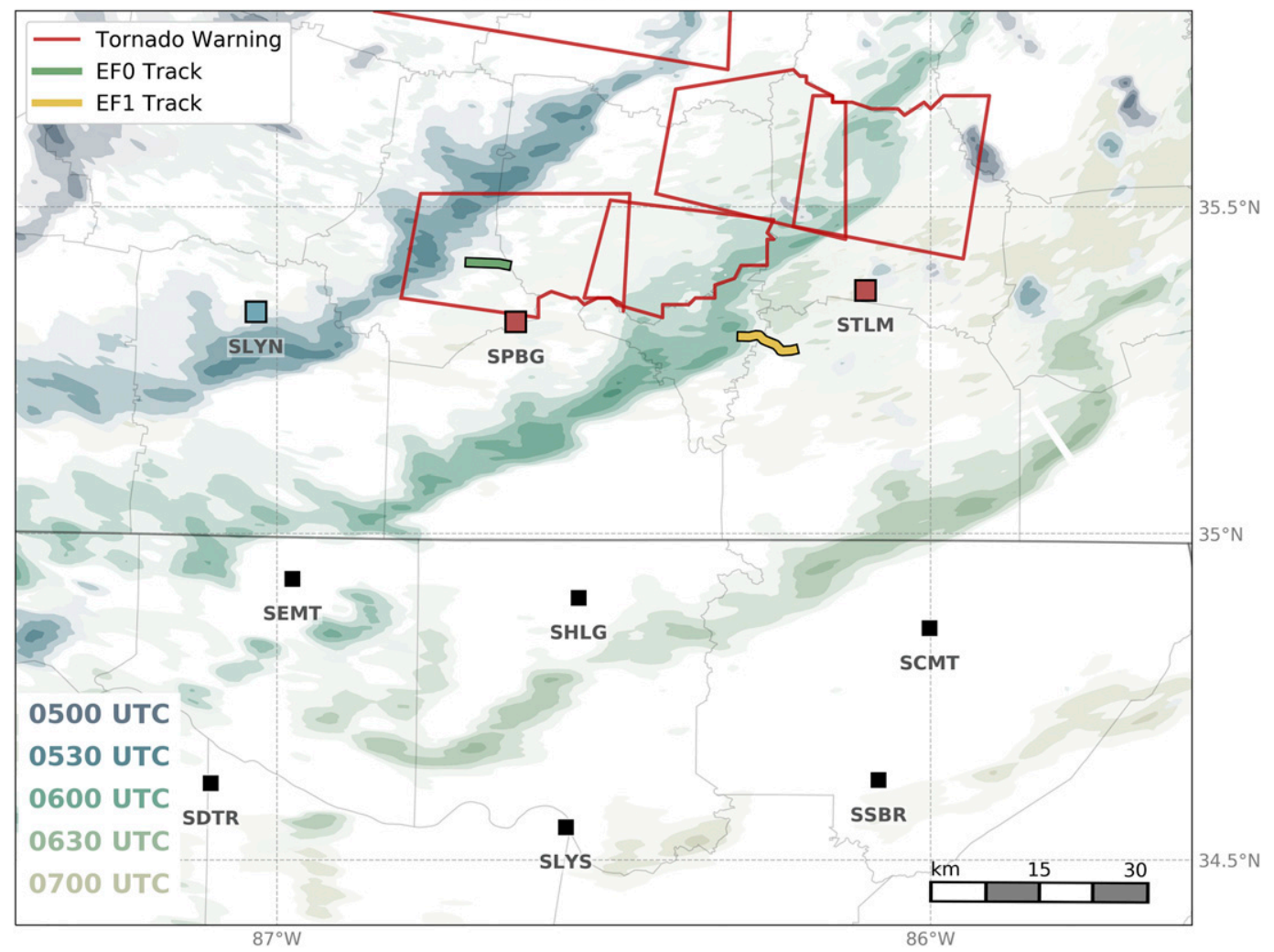

FIG. 4. The 10 Mar 2017 case overview. Shading is KOHX reflectivity, starting at $40 \mathrm{~dB} Z$, with $10 \mathrm{dBZ}$ intervals, colored by half-hour increments. The StickNet colored light blue is near rotation, and the StickNets colored red are near tornadic.

lived than nontornadic mesovortices (Atkins et al. 2004, 2005). In lieu of a detailed radar analysis, which would be hampered by limited quality radar coverage, the following results are based on the assumption that tornadic mesovortices are stronger than their nontornadic counterparts. Therefore, baroclinic mechanisms that have been shown to promote mesovortexgenesis will likewise be assumed to increase tornado potential.

\section{a. 10 March 2017}

On late 9 March and into the early morning of 10 March 2017, a QLCS produced two tornadoes (rated EF0 and EF1) in Tennessee within the VORTEX-SE domain (Fig. 4). Based on criteria used in past literature (e.g., Davis and Parker 2014; Sherburn and Parker 2014), this case has been classified as a "high-shear, low-CAPE" event, with the 13-km Rapid Refresh (RAP; Benjamin et al. 2016) analyzing bulk shear near $60 \mathrm{kt}$ $\left(1 \mathrm{kt} \approx 0.51 \mathrm{~m} \mathrm{~s}^{-1}\right)$ and surface-based CAPE (SBCAPE) under $500 \mathrm{~J} \mathrm{~kg}^{-1}$. Approximately $30 \mathrm{~min}$ before and slightly west of the first tornado (0500 UTC 10 March), RAP analysis shows a small pocket of SBCAPE of $250 \mathrm{~J} \mathrm{~kg}^{-1}$ in a region with little to no convective inhibition (Fig. 5). The CAPE was driven by slightly larger analyzed surface dewpoints and increased lapse rates compared to surrounding areas. While the lapse rates cannot be independently verified, the StesoNet dewpoint field around 0500 UTC showed a similar environmental east-west dewpoint gradient ahead of the QLCS. Conversely, RAP analyzed temperatures were several degrees Celsius too warm compared to the StesoNet. If this region of higher CAPE is represented accurately by the RAP analysis, it may have assisted tornadogenesis through enhancing low-level updrafts and tilting and/or stretching of existing vortex lines. However, it is quite possible that the RAP analysis is insufficiently representing available CAPE, as HSLC environments can undergo rapid destabilization preceding QLCS arrival that is often missed by operational models (King et al. 2017). After producing the tornadoes, the convective line continued to drift southward, losing intensity over time.

The westernmost tornado, rated EF0, passed $9.8 \mathrm{~km}$ north of SPBG (Petersburg, Tennessee). The other tornado, rated EF1, passed as close as $14.2 \mathrm{~km}$ southwest of STLM (Tullahoma, Tennessee). The data gathered by STLM are considered to be less representative than other near-tornado measurements discussed in the results as the tornado barely crossed the $15-\mathrm{km}$ radius. SYLN (Lynnville, Tennessee) also had a mesovortex pass within $15 \mathrm{~km}$, thus qualifying as a nearrotation observation.

Before deficits were calculated, normalized traces of surface variables were compared from each StickNet location to identify any local state relationships potentially relevant to 


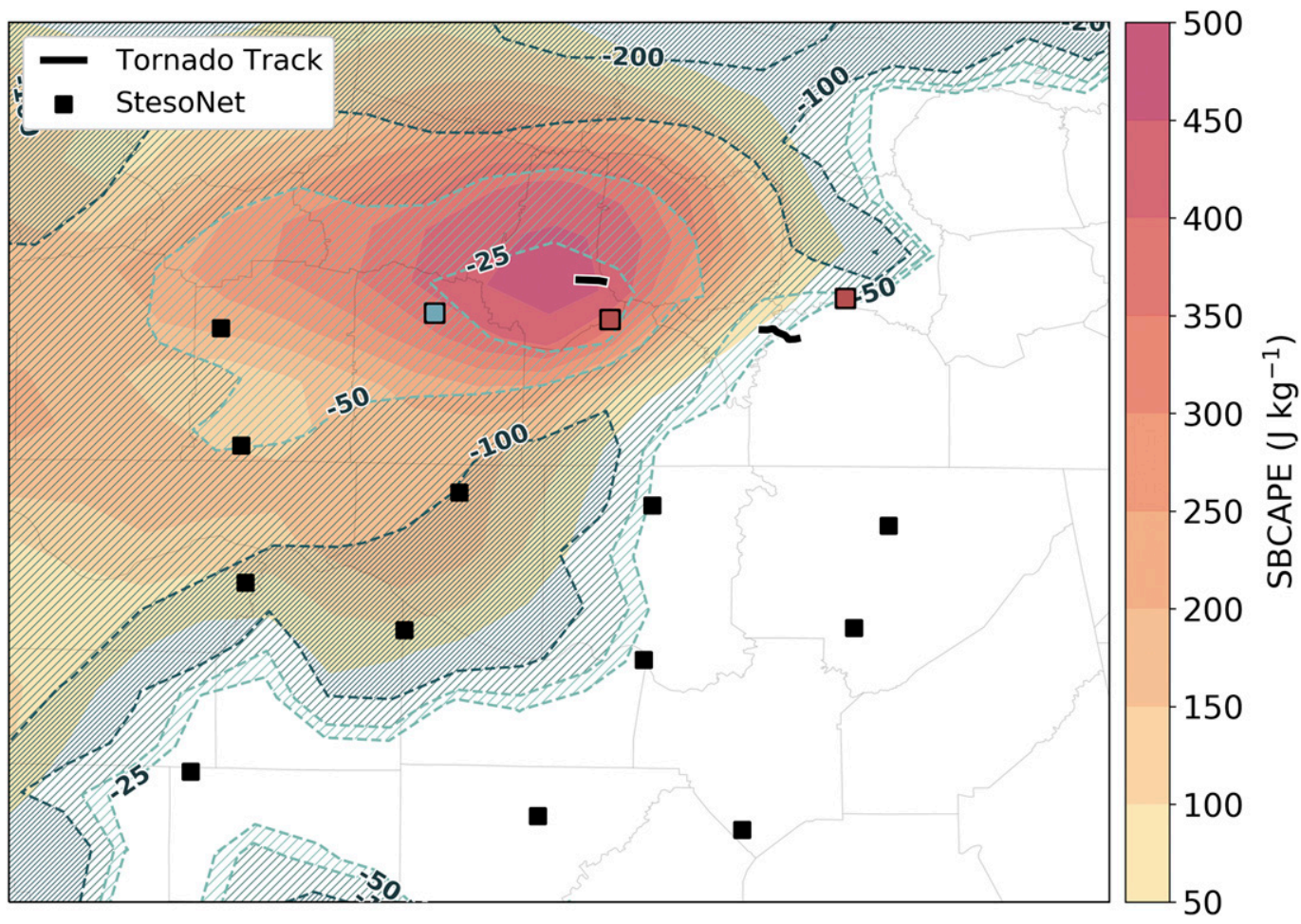

FIG. 5. The 0500 UTC 10 Mar 2017 13-km RAP analysis of SBCAPE (shaded, $\mathrm{J} \mathrm{kg}^{-1}$ ) and SBCIN (hatched in light blue, $\mathrm{J} \mathrm{kg}^{-1}$ ). StickNets are colored as in Fig. 4.

tornado production (Fig. 6). To reduce noise, data were downsampled from 1 to $0.10 \mathrm{~Hz}$ for this specific analysis. The near-tornadic observations (SPBG and STLM), the nearrotation observation (SLYN), and a representative nontornadic observation (SHLG) are included in this analysis. Leading into the cold pool, all observations show increasing wind speed and wind direction shifts of varying magnitude, rising pressure from the increased density within the cold pool, and decreasing temperature traces. The near-tornadic observations both have sharp cold pool edges, with abrupt changes in all variables. The observation nearest a tornado, SPBG, has $\theta_{v}$ and $\theta_{e}$ traces that are nearly indistinguishable from each other. The coincident decreases in $\theta_{v}$ and $\theta_{e}$ suggest an organized cool pool edge, but the baroclinic region is then characterized by decreasing potential buoyancy, which could negatively affect upward accelerations of rotating parcels. Alternatively, the observations from a nonrotating line segment (SHLG) present a better thermodynamic scenario for tornadogenesis assuming a suitable base-state environment: decreasing $\theta_{v}$ collocated with increasing $\theta_{e}$, resulting in a baroclinic region that could have large potential buoyancy relative to its environment. Parcels lifted to their level of free convection would have greater CAPE and less CIN than surrounding parcels, while still containing baroclinically generated horizontal vorticity (assuming favorable parcel trajectories). Skinner et al. (2011) observed a similar thermodynamic situation along the forward flank reflectivity gradient of a tornadic supercell, with the positive $\theta_{e}$ perturbations driven by an increase in water vapor. They concluded that this region was "modified inflow" rather than pure outflow, but were unable to positively determine the source of the water vapor. At SHLG, it is possible that evaporation of light rain that preceded the main QLCS in this region (not shown) may have contributed to the increase in water vapor while also decreasing $\theta_{v}$.

The $\theta_{v}$ and $\theta_{e}$ deficits were calculated for all StickNets, even those outside of a $15-\mathrm{km}$ rotation radius, so that comparison between the nonrotating, near-rotation, and near-tornadic observations could be made. The deficit magnitudes recorded at SPBG (nearest any tornado) were much larger than any other observation within the convective system, with deficit values near 10 and $19 \mathrm{~K}$ in $\theta_{v}$ and $\theta_{e}$, respectively (Fig. 7a). In addition to deficits, the $\theta_{v}$ gradients were also investigated. It was found that the magnitude of the gradient nearest any tornado (from SPBG) was $0.6 \mathrm{~K} \mathrm{~km}^{-1}$ larger than any other observation within this QLCS, including the other tornadic observation from STLM (Fig. 7b). The output of a $t$ test $^{5}$ (with assumed equal variances between the tornadic and nontornadic populations) rejects the null hypothesis that gradients near the tornado reports are from the same population as the other observed gradients ( $p$ value $<0.05$ ), suggesting that the near-tornado gradients are from a different population with statistically greater magnitudes.

\footnotetext{
${ }^{5}$ The $\theta_{v}$ gradient distributions were found to be approximately normal, so use of a $t$ test is appropriate.
} 


\section{March 2017}
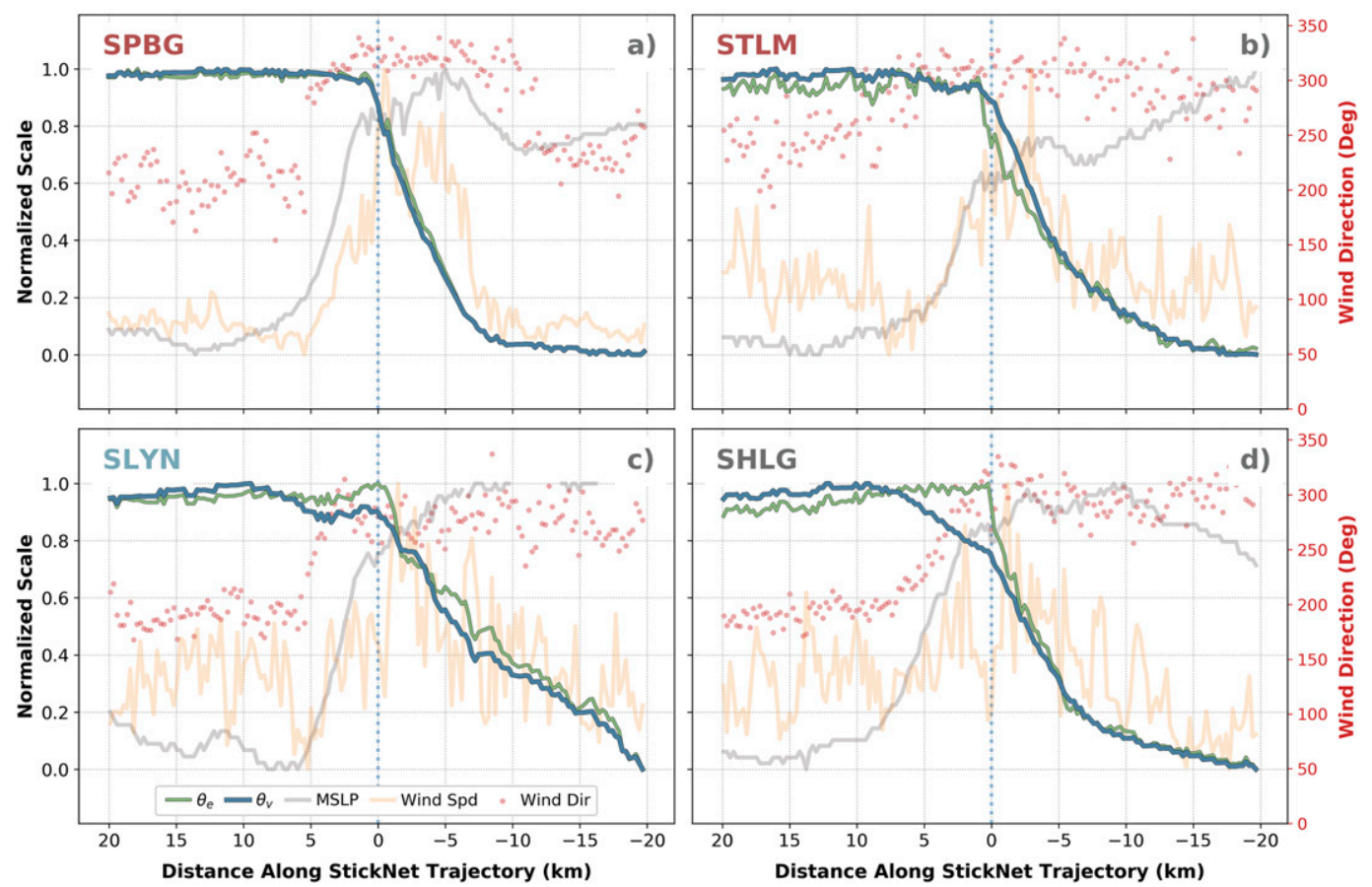

FIG. 6. Normalized variable traces on 10 Mar 2017, downsampled to $0.1 \mathrm{~Hz}$. The $x$ axis is time converted to distance using the storm velocity. Traces show $\theta_{v}$ (blue line), $\theta_{e}$ (green line), MSLP (gray line), wind direction (red scatters), and wind speed (orange line). StickNet IDs in the upper-left corner of each panel are colored according to classification: red is near tornado, blue is near rotation, and gray is located farther than $15 \mathrm{~km}$ from any rotation within the convective system. Data shown are from (a) SPBG, (b) STLM, (c) SLYN, and (d) SHLG.

Last, the deficits and gradients themselves were interpolated onto a grid so that spatial and temporal heterogeneities of the thermodynamic deficits within the QLCS could be seen (Fig. 8). Note that these interpolations do not represent a snapshot in time; the direction parallel to storm motion (in this case, roughly north to south) shows temporal changes, while the perpendicular direction (west to east) shows along-line spatial changes. The northeastern region of the domain near the tornadic activity experienced the largest deficits and $\theta_{v}$ gradients. SPBG is clearly visible with the largest magnitude of all variables. Generally, as the QLCS sagged to the southeast, the magnitude of all of the variables decreased as the system weakened.

\section{b. 30 April 2017}

On 30 April 2017, a tornadic QLCS traversed across the Southeast, producing many tornadoes over the course of the day. The majority of these tornadoes occurred in Mississippi, but the final tornado (around 1900 UTC) was produced in Alabama within the VORTEX-SE domain (Fig. 9). This tornado was rated EF0 and passed within $8.3 \mathrm{~km}$ of the SCLM (Cullman, Alabama) StickNet. Inspection of the KHTX radar data shows the preliminary tornado track does not line up with the region of enhanced shear associated with the nearby mesovortex (Fig. 10), which was observed at a beam height of approximately $1.4 \mathrm{~km}$. However, the tornado damage survey from NWS Huntsville noted damage that fell in a "convergent" or "sporadic" pattern, suggesting it was not caused by straight-line winds. Numerical simulations of HSLC embedded supercells have shown that surface vortices can have motions that are quite different from the midlevel $(3-5 \mathrm{~km})$ rotating updrafts (Sherburn and Parker 2019, their Figs. 5 and 19), so the disconnect between the radar signature and the tornado track is not unprecedented. However, given the conflicting information, the mesovortex near this tornado report will be referred to as "near tornadic" rather than tornadic. The near-tornadic mesovortex also came within $15 \mathrm{~km}$ of SADN (Addison, Alabama) and SLYS (Lacey's Spring, Alabama), although it was not tornado-warned during this time. North of the tornado, two nontornadic mesovortices developed and also impacted the StesoNet (SHYL, SLGN, SEMT, SDTR) and four rapid StickNets from a finescale deployment, allowing for comparison between near-tornadic and nontornadic mesovortices within this QLCS (Fig. 11). The northernmost nontornadic mesovortex was also tornado-warned.

The RAP analysis at 1900 UTC showed $50 \mathrm{kt}$ of bulk wind shear along with SBCAPE values of at least $500 \mathrm{~J} \mathrm{~kg}^{-1}$, with values as high as $1300 \mathrm{~J} \mathrm{~kg}^{-1}$ over the eastern StesoNet (not shown). A special sounding released at 1800 UTC south of the 


\section{March 2017}

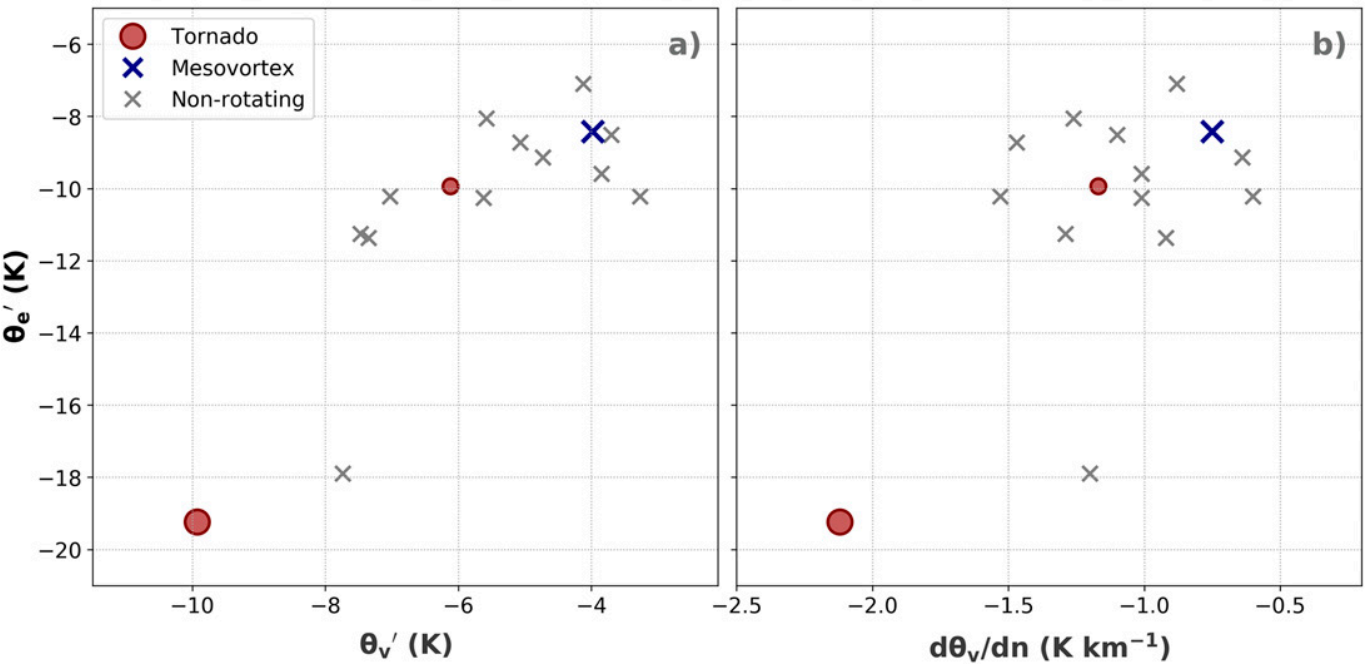

FIG. 7. Cold pool deficits from 10 Mar 2017 plotted with the $\theta_{e}(\mathrm{~K})$ perturbations on the $y$ axis and either (a) $\theta_{v}$ (K) perturbations or (b) $d \theta_{v} / d n\left(\mathrm{~K} \mathrm{~km}^{-1}\right)$ on the $x$ axis. For both (a) and (b), the large red circle represents the observations from SPBG, which was closest to any tornado $(9.8 \mathrm{~km})$. The smaller red circle denotes the observations from STLM, which was near a tornado $(14.2 \mathrm{~km})$, but more distant than SPBG. The dark blue $\times$ symbol is from SLYN which was near storm-scale rotation but no tornado. The gray $\times$ symbols show observations from other, nonrotating parts of the QLCS.

domain in Birmingham, Alabama, observed SBCAPE of $1510 \mathrm{~J} \mathrm{~kg}^{-1}$. The 1800 and 1900 UTC RAP analyzed a pocket of mixed-layer CIN (MLCIN) exceeding magnitudes of $100 \mathrm{~J} \mathrm{~kg}^{-1}$ near the northern nontornadic mesovortices. The MLCIN was driven by slightly lower surface dewpoints and warmer temperatures at $800 \mathrm{hPa}$. MLCIN of that magnitude is more typically associated with nontornadic QLCS events (Thompson et al. 2012), and may have played a role in reducing the tornado threat in that region. While the upperlevel representation of the RAP cannot be confirmed, the StesoNet did sample a region of lower dewpoints associated with the area of higher MLCIN. A base-state analysis also showed a gradient of $\theta_{e}$ across the domain, with higher values to the south, near the tornado, suggesting that environmental heterogeneity may have also been a factor for this event.

Just as in the 10 March event, plots of normalized variables were analyzed at the cold pool edge to see if any of the raw or derived variables effectively discriminated between the nontornadic and near-tornadic mesovortex samples (Fig. 12). SCLM (nearest the tornado) and SADN represent the neartornadic mesovortex, and 0222A (labeled in Fig. 11) and SEMT are associated with the southern and northern nontornadic mesovortices, respectively. The results are similar to what was found in the 10 March case, with the StickNet nearest a tornado (SCLM) recording one of the more abrupt cold pool edges observed in the entire QLCS (not shown), with variables that all sharply inflect simultaneously. 0222A also observed a cold pool edge characterized by coincident inflections in all variables, with remarkable similarities to the SCLM data. Interestingly, none of the nearby rapid StickNets recorded a cold pool edge with gradients as sharp as at $0222 \mathrm{~A}$, which implies that this region had a very small horizontal extent (approximately less than $10 \mathrm{~km}$ ). The only apparent difference between $0222 \mathrm{~A}$ and SCLM is that $0222 \mathrm{~A}$ records a sharper relative decrease in $\theta_{v}$ prior to cold pool arrival than SCLM.

Unlike the 10 March event, near-tornadic and nontornadic regions of the QLCS cannot be discriminated clearly by the cold pool deficits themselves (Fig. 13a). Generally, the tornado-warned nontornadic mesovortex exhibits the smallest deficits, while the southern nontornadic mesovortex and near-tornadic mesovortex deficits vary. The deficits from nearest the tornado are roughly average, with $\theta_{e}$ deficits that are about $1 \mathrm{~K}$ warmer than the average perturbation of $-8.7 \mathrm{~K}$ for this QLCS and $\theta_{v}$ deficits that are $0.5 \mathrm{~K}$ cooler than average $(-6.8 \mathrm{~K})$. These results generally follow Markowski et al. (2002), who found that weakly tornadic and nontornadic supercells had similar deficits.

The results from the $\theta_{v}$ gradients show a clearer signal. The cold pool observations associated with the near-tornadic mesovortex have larger $\theta_{v}$ gradients than most other parts of the convective line (Fig. 13b), with only two observations of stronger gradients. The large gradients imply that this region of the QLCS may have consistently had the greatest baroclinic vorticity generation of any other location, assuming favorable parcel trajectories across the gradient. The larger gradients near the tornadic activity are as strong or stronger than the gradient found closest to a tornado in the 10 March case, and a $t$ test confirmed that gradients associated with the near-tornadic mesovortex come from a different 
10 March 2017
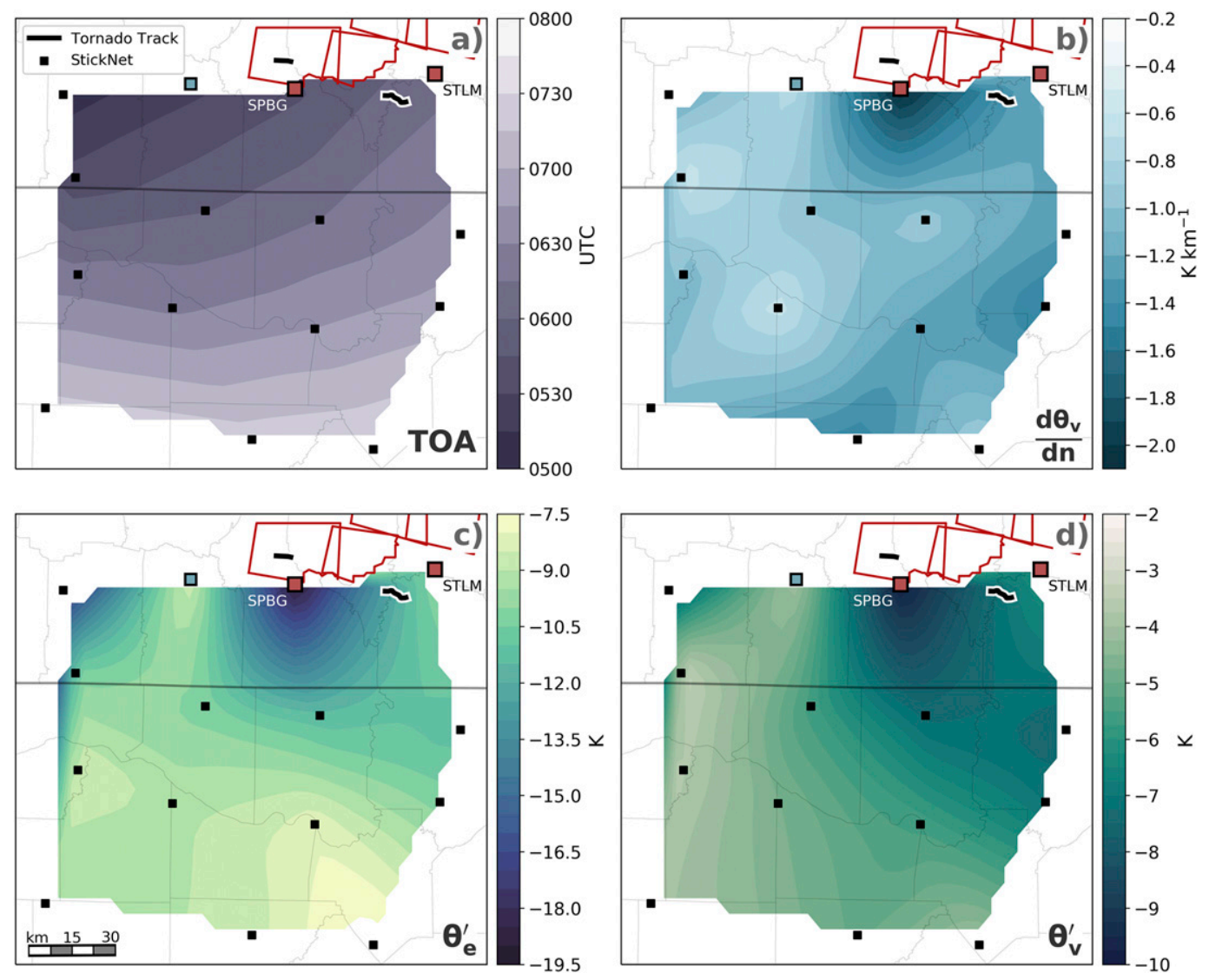

FIG. 8. Cold pool buoyancy deficits and gradients for the 10 Mar 2017 QLCS. Shown are (a) TOA (UTC), (b) $\theta_{v}$ gradients $\left(\mathrm{K} \mathrm{km}^{-1}\right)$, (c) $\theta_{e}$ deficits $(\mathrm{K})$, and (d) $\theta_{v}$ deficits $(\mathrm{K})$. Due to the orientation of the TOA contours, changes in the horizontal show along-line spatial heterogeneities, while changes in the vertical show temporal heterogeneities. The red polygons denote the locations of the tornado warnings.

population than the rest of the observed gradients within the parent QLCS. Additionally, of the seven observations with $d \theta_{v} / d n$ stronger than $-2 \mathrm{~K} \mathrm{~km}^{-1}$, observations near the tornado and near-tornadic mesovortex had the third and second weakest $\theta_{e}$ deficits, respectively. Thus, the regions near the near-tornadic mesovortex may have been more potentially buoyant than other large $\theta_{v}$ gradient regions. Buoyant accelerations may have been a contributing factor for strengthening the near-tornadic mesovortex and potentially tornadogenesis itself, as having relatively small negative $\theta_{e}$ perturbations collocated with enhanced baroclinity is ideal for the production, tilting, and stretching of vorticity.

Last, the interpolated buoyancy gradients and deficits help to identify patterns within the QLCS itself (Fig. 14). The neartornadic mesovortex occurred in a region of the storm that had relatively larger $\theta_{v}$ gradients compared to surrounding regions; the StickNet intercept immediately preceding the tornado (SADN) had the second largest observed gradient (Fig. 14b). Additionally, the near-tornadic mesovortex rapidly strengthened following the intercept at SADN, suggesting that the stronger $\theta_{v}$ gradients may have produced more baroclinic vorticity which could have promoted mesovortexgenesis. The deficits also revealed patterns with two streaks of weaker $\theta_{e}$ and $\theta_{v}$ deficits following the paths of the near-tornadic and northern nontornadic mesovortices (Figs. 14c,d). These weaker deficits could be indicative of hydrometeor loading or dynamic forcing (from nonhydrostatic pressure gradients) causing the decent of updraft parcels within the downdraft (Markowski et al. 2002).

\section{c. All events}

In addition to the two tornadic QLCS events, observations were collected from seven other events of varying convective mode (Fig. 15; Table 1). The most prominent of these events was a tornadic supercell event on 22 April 2017. Two tornadic supercells tracked across the StesoNet, producing an EF0 and EF1 tornado that each came within $15 \mathrm{~km}$ of a StickNet. A detailed case study of this event (or any other event) will not be included in this paper, as the main focus is on tornadic linear systems. However, the data will be included for the purpose of broad conclusions for all cold pools sampled during the experiment. 


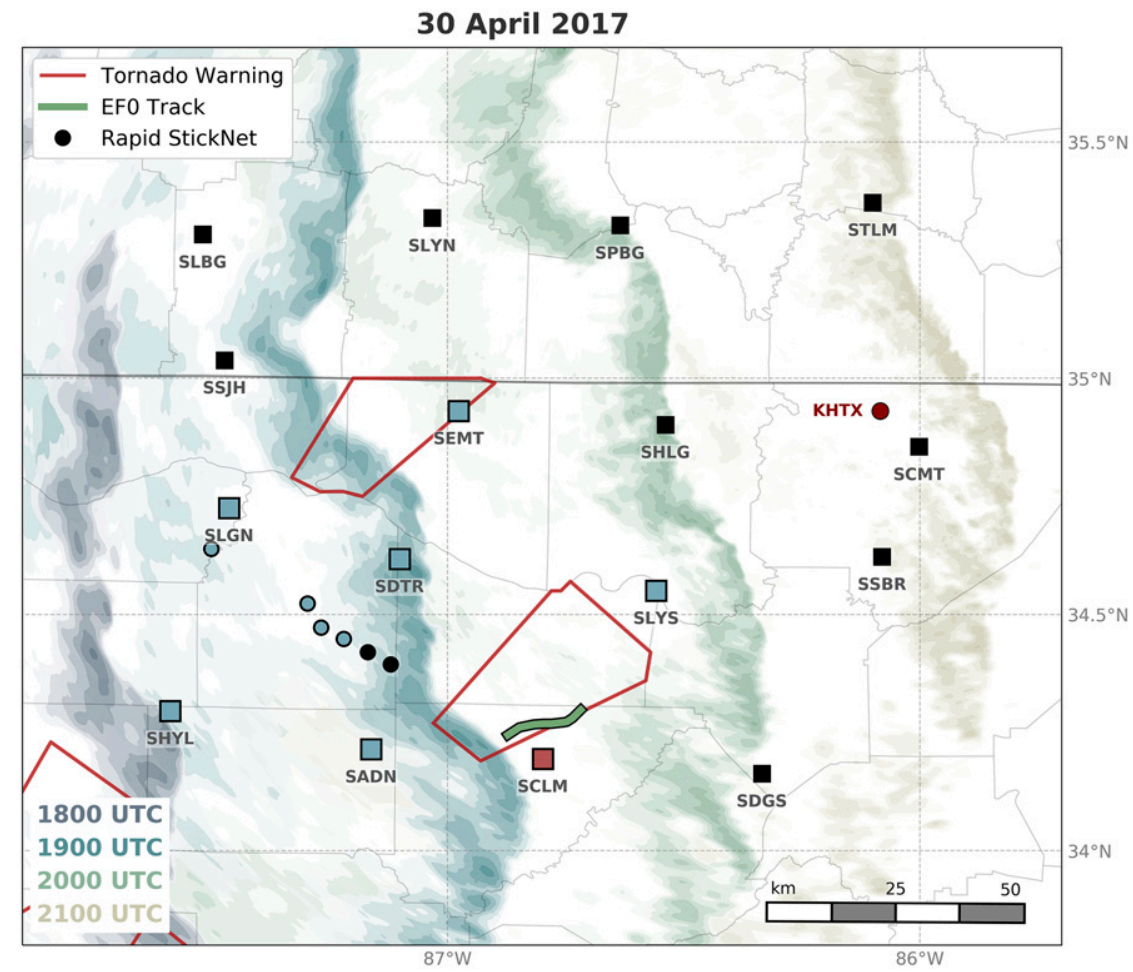

FIG. 9. The 30 Apr 2017 case overview, as in Fig. 4. KHTX radar reflectivity is shaded in hourly increments.

The deficit and gradient results collected from all nine events were plotted together to allow for tornadic and nontornadic observation comparison, as well as comparison across modes (Fig. 16a). Analysis of the observations reveal no clear difference between tornadic and nontornadic deficits. However, there is a relationship between event mode and these deficits. The linear events have the largest average $\theta_{v}$ deficits, followed by hybrid mode and then supercell mode. The pattern is nearly the same for $\theta_{e}$ deficits; however the supercell observations show slightly larger deficits than the hybrid mode. Although the $\theta_{v}$ gradients appeared fairly effective in differentiating near-tornadic observations from the others in the individual tornadic QLCS cases, the signal is lost when all of the measurements are compared (Fig. 16b). This inconsistency could mean that considering $\theta_{v}$ gradients is only useful for assessing tornado potential in a relative sense for a single case (e.g., along a specific extent of a mature QLCS), which is not surprising given the base-state environment at the surface and aloft can be significantly different across cases. Looking across the modes, the $\theta_{v}$ gradient averages follow the same pattern as
1912 UTC

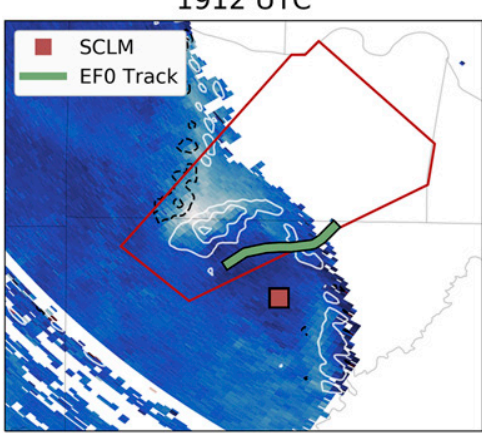

1917 UTC

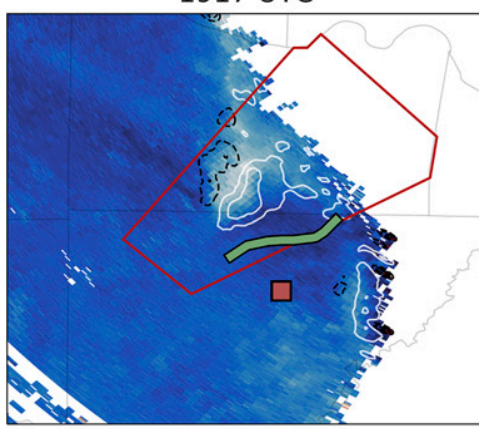

1922 UTC

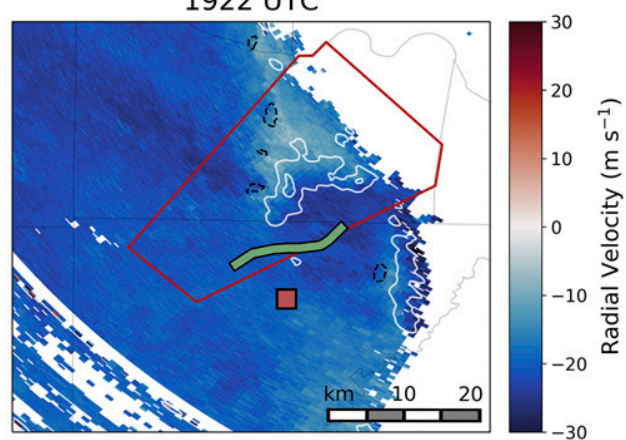

FIG. 10. KHTX radial velocity $\left(\mathrm{m} \mathrm{s}^{-1}\right.$ ) on 30 Apr 2017 of the southern mesovortex. The green line is the EF0 tornado track, the blackbordered square is the location of the SCLM StickNet, and the red outline is the tornado warning polygon. Inferred cyclonic vorticity [calculated using Eq. (1) and smoothed with a Gaussian filter] is contoured in white, starting at $0.002 \mathrm{~s}^{-1}$ and plotted every $0.004 \mathrm{~s}^{-1}$. Anticyclonic vorticity is contoured with black dashes at the same magnitudes. 

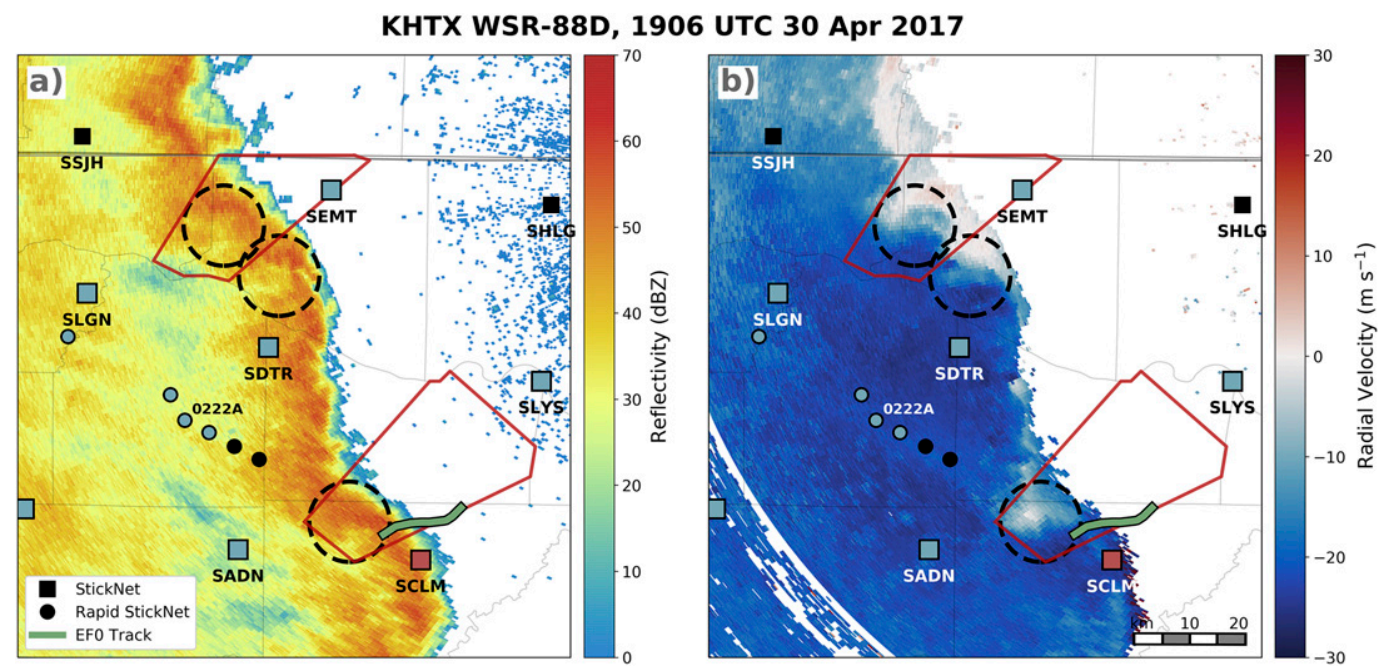

FIG. 11. KHTX (a) reflectivity (dBZ) and (b) radial velocity $\left(\mathrm{m} \mathrm{s}^{-1}\right)$ on $30 \mathrm{Apr} 2017$. The three mesovortices are circled with black dashes. The two northern mesovortices were nontornadic; the southern mesovortex was near-tornadic. The StickNets are colored by classification as in Fig. 4. The red boxes denote the locations of the tornado warning polygons.

the $\theta_{v}$ deficits, with QLCS mode recording the largest average gradients, proceeded by hybrid and then supercell.

\section{Discussion}

\section{a. $\theta_{v}$ and $\theta_{e}$ deficits}

As mentioned in the section 3, there are no clear differences between the deficits observed near tornadoes and those recorded near nontornadic storms or line segments with stormscale rotation (Fig. 16a). One explanation may lie with the strength of the tornadoes in the storms sampled, as past research has found that weakly tornadic (EF1 or weaker) and nontornadic storms have deficits that are similar in magnitude e.g., Markowski et al. (2002), Shabbott and Markowski (2006), and Weiss et al. (2015). It could be argued that the high boundary layer moisture (i.e., reduced evaporative potential)

\section{April 2017}
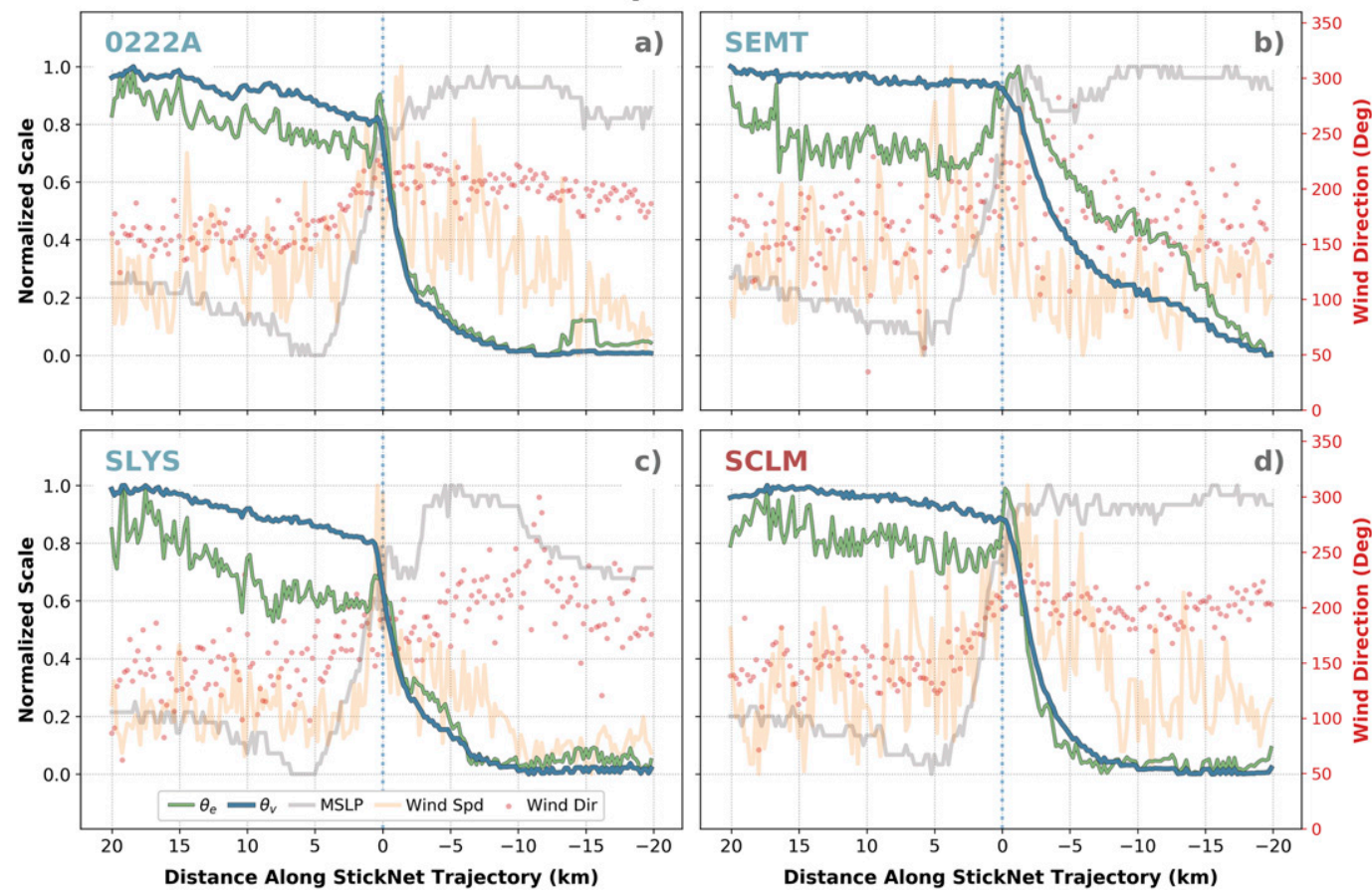

FIG. 12. Normalized variable traces on 30 Apr 2017, as in Fig. 6, but for (a) 0222A, (b) SEMT, (c) SLYS, and (d) SCLM. 
30 April 2017

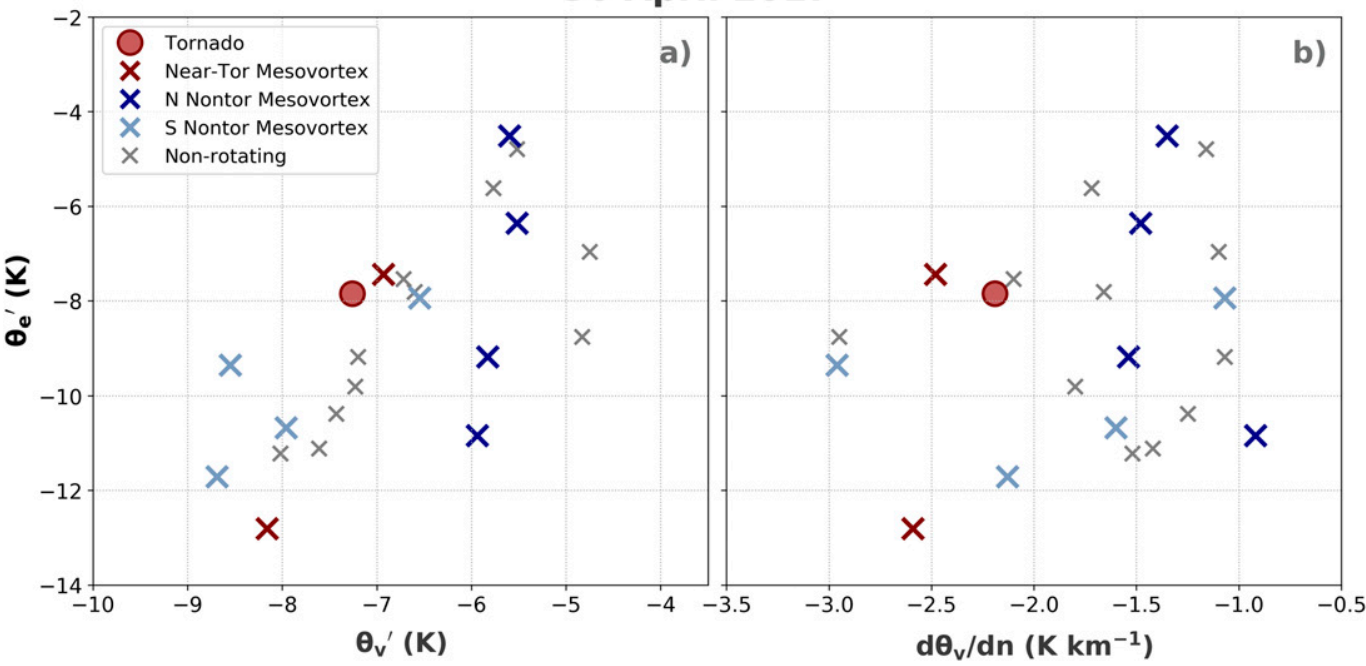

FIG. 13. Deficits observed on 30 Apr 2017, as in Fig. 7. Since there were two nontornadic mesovortices, observations from the northern mesovortex are colored dark blue and observations from the southern mesovortex are light blue. The observations within $15 \mathrm{~km}$ of the near-tornadic mesovortex, but not near the tornado, are colored red.

that often characterizes Southeast U.S. convective environments would diminish both the magnitude and variance in cold pool deficits, thereby minimizing characteristic differences between tornadic and nontornadic cold pools. However, the deficits presented here span a wide range of values (Fig. 16a). Additionally, a comparison between base-state dewpoint depression $\left(T_{\mathrm{dd}}\right)$ and $\theta_{v}$ deficits (Fig. 17) results in a best-fit line with a slope of -0.499 and a linear correlation $(r)$ of -0.62 , a result that is remarkably similar to that found by an analogous comparison Markowski et al. (2002, their Fig. 15) performed for Great Plains supercells. Given that the base-state dewpoint depression range is decently large (up to $10 \mathrm{~K}$ ), it is likely that consistently high values of ambient moisture did not play a significant role in similarity of the tornadic and nontornadic cold pool deficits.

A clear signal in the deficits is found when comparing event mode. The linear mode had the coldest average cold pools, which is expected given that stronger cold pools promote the development of linear systems (Weisman and Davis 1998; James et al. 2006). One of the largest deficits recorded across all cases was near a tornado that occurred during a linear event (10 March 2017). While large, these magnitudes are similar to the deficits recorded within $4 \mathrm{~km}$ of an $\mathrm{F} 1$ supercell tornado (Markowski et al. 2002), so they are not unprecedented. Additionally, stronger deficits can be associated with greater convergence (stronger horizontal hydrostatic pressure gradients), leading to enhanced lift. Therefore, in the case of this observation, the large deficits may mean this segment of the storm had a strong low-level updraft, despite having the least amount of buoyancy compared to the rest of the line.

\section{b. $\theta_{v}$ gradients}

The results from the 10 March and 30 April case studies suggest that $\theta_{v}$ gradients may differentiate between tornadic and nontornadic mesovortices or line segments. Both events had large $\theta_{v}$ gradients near a reported tornado or a mesovortex that produced a tornado during its lifetime, excluding one of the tornadic observations from the 10 March case (which may be less representative than the other tornadic observations due to tornado-observation distance). The large gradients near the other tornadoes imply that tornadogenesis-capable regions of the linear systems were characterized by strong temperature gradients, and, thus, potentially larger horizontal baroclinic vorticity generation which could be important for producing and maintaining mesovortices capable of tornadogenesis. However, enhanced baroclinic vorticity generation would only be possible if air parcels followed paths that allowed them to take advantage of the strong $\theta_{v}$ gradient before being tilted, a scenario that, though plausible given the parcel trajectories numerically depicted by Xu et al. (2015, their parcel P2), Flournoy and Coniglio (2019, their "environmental parcels"), and, to a lesser extent, Atkins and St. Laurent (2009b, from the "cellular stage"), cannot be proven without a trajectory analysis of parcels flowing into the areas of low-level vertical vorticity.

Past radar studies of QLCS events, particularly bowing segments, have found that tornadic mesovortices tend to form near a bowing segment and/or RIJ (Atkins et al. 2004, 2005). RIJs act to locally increase convergence along the gust front, presumably increasing vertical stretching of existing vertical vorticity. A detailed examination of RIJs in radar data is outside the scope of this research and would be difficult given relatively poor radar coverage and outages; however, it appears that the three tornadic or neartornadic mesovortices occurred north of bowing structures. While it is not possible to directly relate RIJ-induced gust front convergence and the stronger baroclinic regions 
30 April 2017
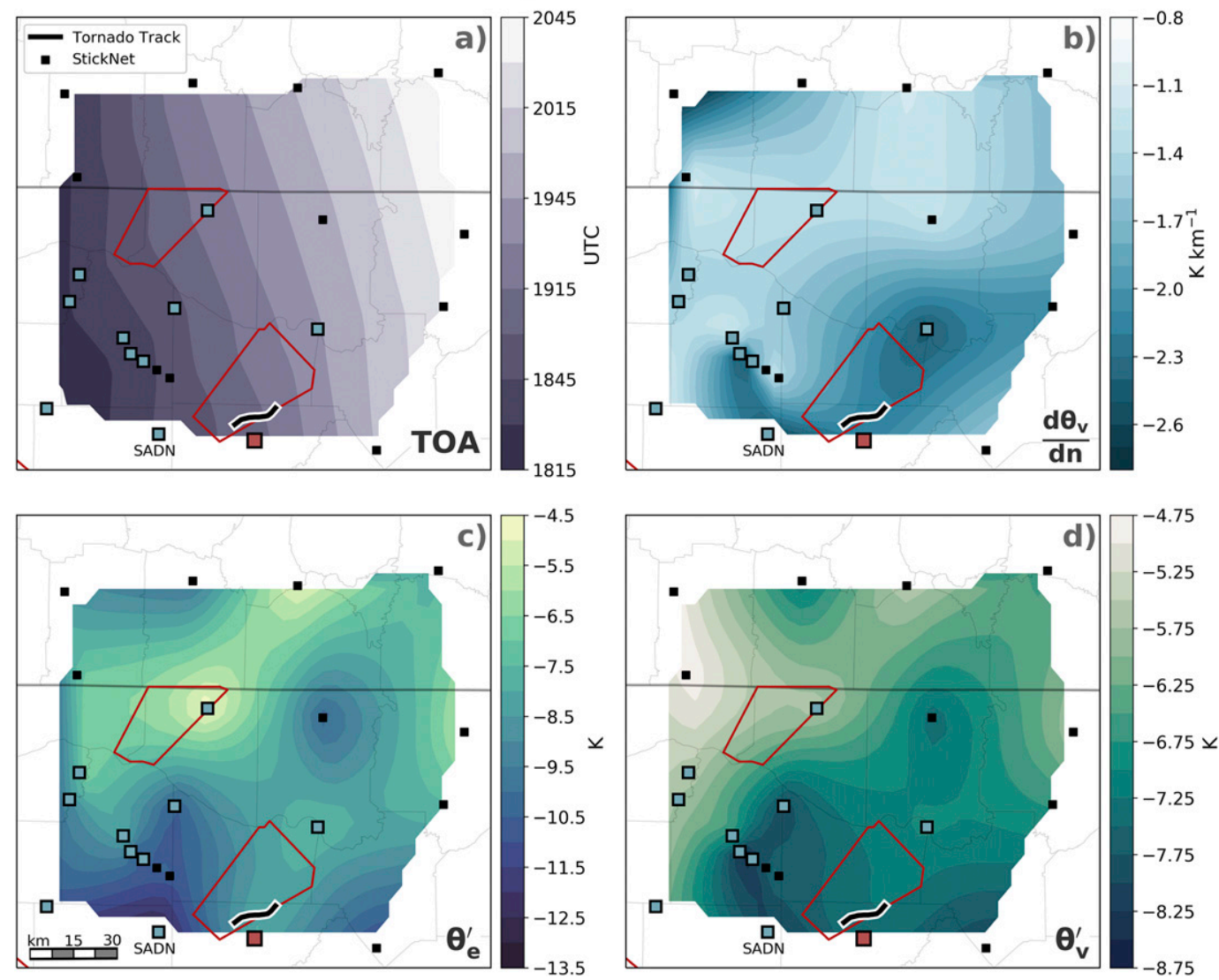

FIG. 14. The 30 Apr 2017 cold pool buoyancy and gradients, as in Fig. 8. Due to the orientation of the TOA contours, changes in the vertical show along-line spatial heterogeneities, while changes in the horizontal show temporal heterogeneities.

given the analyses presented here, there is at least precedence for features that promote tightening temperature gradients near mesovortices capable of tornadogenesis.

On 30 April 2017, the observations collected at SADN combined with radar imagery suggest that the Trapp and Weisman (2003) mechanism for tilting baroclinic vorticity via the downdraft may have been a factor in the strengthening the near-tornadic mesovortex. The strong cold pool combined with large $\theta_{v}$ gradients at SADN (Figs. 14b-d) suggests that baroclinically generated vortex lines enhanced by the strong gradient may have been depressed by the stronger downdraft associated with the larger $\theta_{v}$ deficits. This configuration would lead to a cyclonic vortex on the south side of the reoriented vortex lines and an anticyclonic vortex to the north, as shown by Trapp and Weisman (2003; their Fig. 23). Both anticyclonic and cyclonic mesovortices are visible in KHTX radial velocities and inferred vertical vorticity fields, especially at 1912 UTC (Fig. 10). The mesovortices were evident on radar for some time, but they visibly intensified shortly after the strong $\theta_{v}$ gradient was observed at SADN (not shown). A tornado warning was issued for the quickly strengthening near-tornadic mesovortex approximately $20 \mathrm{~min}$ after the observations at SADN.
The gradients associated with the tornadic supercells have split results; one of the observations has a strong gradient relative to the supercell average, while the other is weaker than average. Due to the small number of observations little more can be gathered from these results.

\section{Conclusions}

During the VORTEX-SE campaign, StickNet surface observing platforms recorded 39 cold pool observations associated with individual rotating cells or linear systems with embedded mesovortices. The main effort of this study was to identify any cold pool characteristics that could be related to tornadogenesis from two tornadic linear events, with a focus on baroclinic regions at the cold pool edge. Additionally, the data from all the events were explored to see if differences existed between the cold pool deficits of different modes, if deficits discriminated between tornadic and nontornadic storms/line segments, and if, generally, consensus findings from the existing body of observational supercell studies can be applied to other convective modes. These analyses resulted in the following conclusions: 

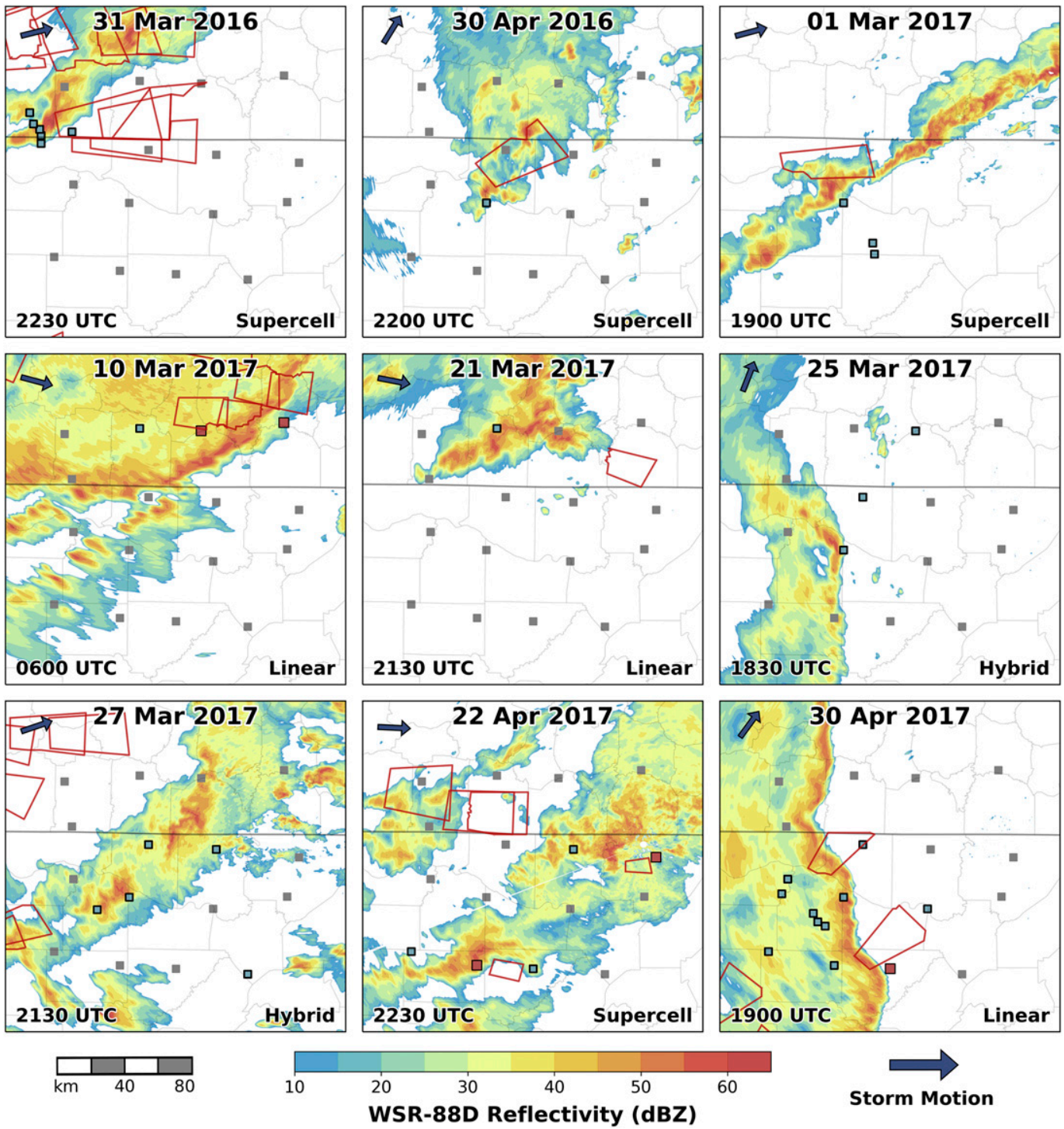

60

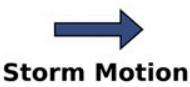

FIG. 15. Representative reflectivity data for each of the nine events in Table 1. Each plot has the lowest available radar reflectivity (shaded, $\mathrm{dBZ}$ ) from near the time listed in the lower-left corner, with average storm motion shown with a blue arrow in the upper-left corner. The storm mode categorization is listed in each lower-right corner. The red polygons are cumulative (24-h) tornado warnings from each event. The StickNets are represented with squares and are colored as in Fig. 4. The red and blue StickNets are those included in the overall analysis (Fig. 16). All reflectivity data are from KHTX except for 10 Mar 2017, which uses KOHX.

1) In the $Q L C S$ events, observations near tornadic mesovortices were often characterized by greater relative baroclinity than those found within the rest of the parent QLCS. The stronger gradients imply enhanced baroclinic vorticity generation which may provide a vorticity source for the genesis and/or maintenance of mesovortices capable of producing tornadoes. However, the relationship between tornadic mesovortices and greater baroclinity breaks down when comparisons are made across cases, suggesting that if baroclinity plays a substantial role in mesovortex genesis and maintenance, then the magnitude of baroclinity needed for this process may be dependent on a host of other environmental or storm-scale conditions (e.g., ambient low-level vertical wind shear, basestate buoyancy).

2) Deficit magnitudes vary based on storm mode (supercell, hybrid, or linear). Linear systems had an average $\theta_{v}$ deficit that was larger than the other modes, and supercell deficits were the weakest. This distinction is likely due to linear systems requiring robust cold pools to propagate and maintain the convective line (in addition to buoyant accelerations), whereas supercells rely more on buoyancy and dynamic pressure perturbations (attributable largely to vertical vorticity) for maintenance. 


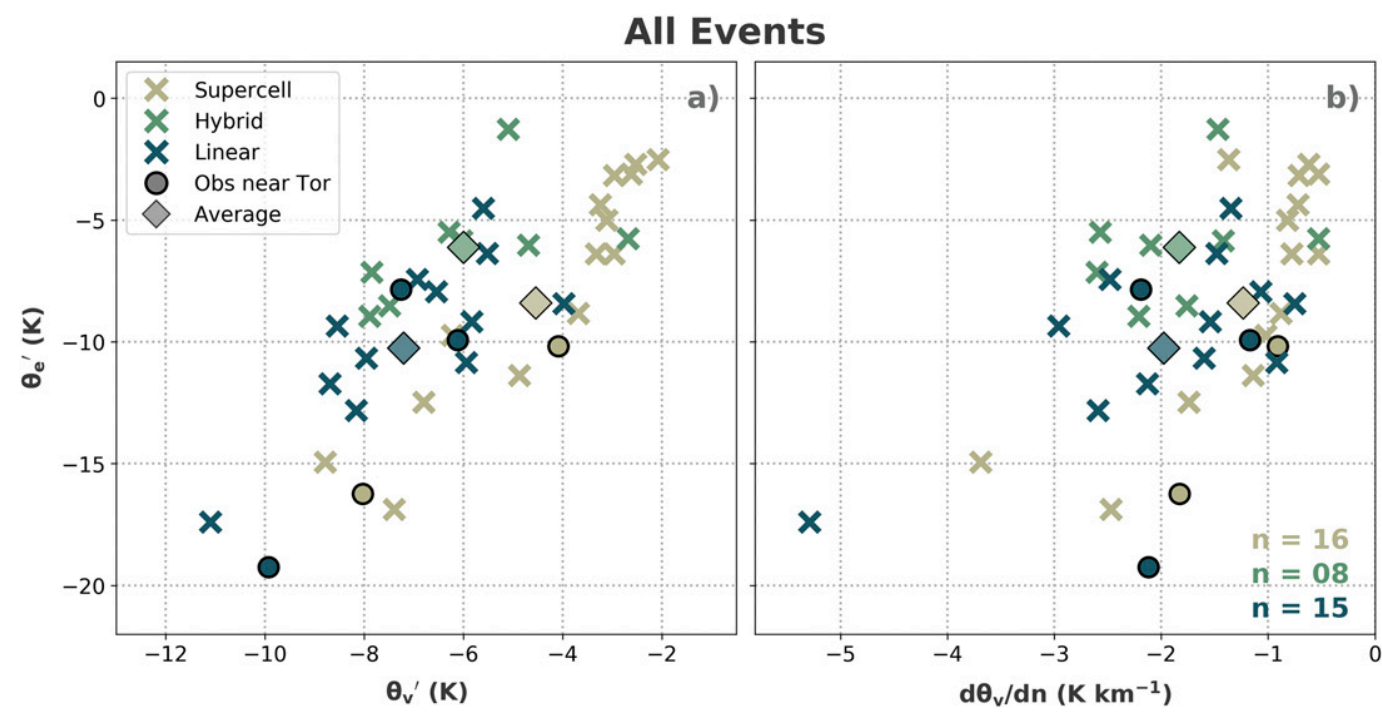

FIG. 16. Cold pool deficits from all 39 qualifying observations, as in Fig. 7. Observations near storm-scale rotation are marked with $\times$, near-tornado observations are plotted with circles, and the average for each mode is shown as a diamond. Supercell observations are colored tan, hybrid events are green, and observations from linear systems are blue. The number of observations from each mode is shown in the lower -right corner of (b), colored by mode.

3) No clear difference was found between the $\theta_{v}$ and $\theta_{e}$ deficits of tornadic and nontornadic cells or line segments. The results are inconclusive due to the few tornadic observations gathered (five total) and the weakness of the tornadoes. Since the strongest tornado that impacted the StesoNet was an EF1, these results agree with past studies that found weakly tornadic supercells and nontornadic supercells to have similar $\theta_{v}$ and $\theta_{e}$ deficit magnitudes e.g., Markowski et al. (2002), Shabbott and Markowski (2006), and Weiss et al. (2015). These findings suggest that the different modes of convection presented in this study may follow similar deficit patterns observed within supercell observations, although this cannot be stated with certainty without measurements of strongly tornadic cells or line segments.

While both 10 March and 30 April found larger relative gradients near tornadic mesovortices, it is important to note that both events occurred in quite different environmental conditions. 10 March was an HSLC nighttime event, whereas 30 April affected the StesoNet domain during the afternoon, in an environment characterized by moderate CAPE. The differences between HSLC and higher CAPE convection, especially the origin of mid and low-level vertical vorticity, is still an open research area. Thus, the baroclinity found in these two QLCS events may not have contributed to the production and maintenance of the tornadic or near-tornadic mesovortices in equal fashion.

Despite the many layers of complexity, the novel dataset presented here suggests that additional observational and theoretical work should focus on the importance of $\theta_{v}$ gradient magnitudes for mesovortexgenesis and tornadogenesis within QLCS events. Additionally, samples of strongly tornadic supercells or line segments would help determine if these storm modes follow the same deficit patterns associated with (largely, Great Plains) mesocyclonic tornado production in prior studies, or if they are characterized by unique cold pool structures. Increasing the number of cold pool observations would also allow for more robust statistical analyses to be undertaken. Ongoing field work is pursuing the observations needed to continue investigation into these questions in the realm of Southeast U.S. tornadic convection.

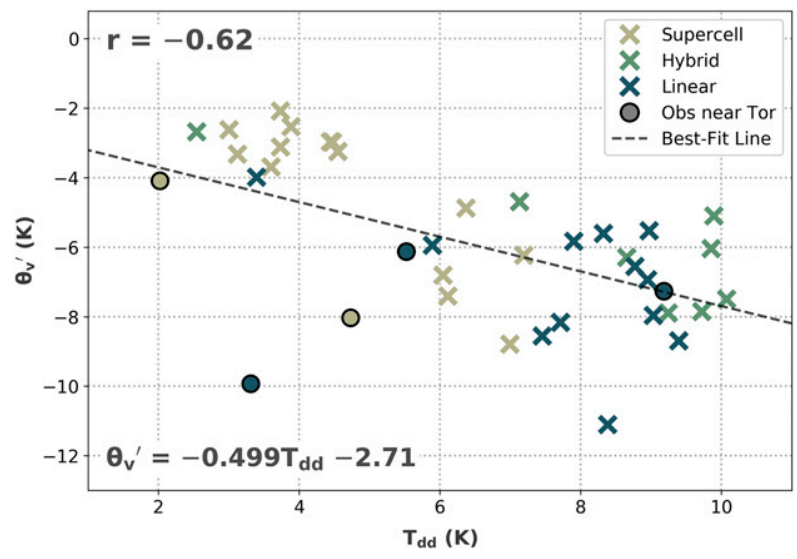

FIG. 17. Plot of $\theta_{v}$ deficits compared to the base-state dewpoint depression $\left(T_{\mathrm{dd}}\right)$ from all 39 qualifying observations, as in Fig. 16. The linear correlation $(r)$ is shown in the upper -left corner, and the equation for the best-fit line is shown in the lower-left corner. 
Acknowledgments. This work was supported by National Oceanic and Atmospheric Administration Grants NA16OAR4590227 and NA17OAR4590206. We thank Dr. Vanna Chmielewski, Dr. Aaron Hill, Dr. Eric Bruning, and Abby Hutson for their work in deploying and maintaining the StickNets during this project and providing assistance with developing the coding infrastructure to analyze the StickNet data. We are also grateful for the helpful comments from Dr. Matt Parker and two anonymous reviewers that improved the quality of this work. The interpolated fields in Figs. 8 and 14 were produced using the MetPy Python package (May et al. 2020), the WSR88D data in Figs. 3, 4, 9, 11, 10 and 15 were plotted using the PyART Python package (Helmus and Collis, 2016), and the base maps in Figs. 1, 4, 5, 8, 9, 10, 11, 14 and 15 were provided by Cartopy (Met Office 2015). The 13-km RAP data were accessed and processed using the Siphon Python package (May et al. 2017).

Data availability statement. All StickNet data used in this paper are available by request. The StickNet data from 2016 are available at https://doi.org/10.5065/D65H7DP7, and the data from 2017 are available at https://doi.org/10.5065/ D6XG9PWG, courtesy of the NCAR Earth Observing Laboratory's data archives. As of the time of the composition of this manuscript, the 13-km RAP analysis data were available at https://www.ncdc.noaa.gov/data-access/modeldata/model-datasets/rapid-refresh-rap.

\section{REFERENCES}

Atkins, N. T., and M. St. Laurent, 2009a: Bow echo mesovortices. Part I: Process that influence their damaging potential. Mon. Wea. Rev., 137, 1497-1513, https://doi.org/10.1175/ 2008MWR2649.1.

$\longrightarrow$, and — 2009b: Bow echo mesovortices. Part II: Their genesis. Mon. Wea. Rev., 137, 1514-1532, https://doi.org/ 10.1175/2008MWR2650.1.

—, J. M. Arnott, R. W. Przybylinski, R. A. Wolf, and B. D. Ketcham, 2004: Vortex structure and evolution within bow echoes. Part I: Single-Doppler and damage analysis of the 29 June 1998 derecho. Mon. Wea. Rev., 132, 2224-2242, https://doi.org/ 10.1175/1520-0493(2004)132<2224:VSAEWB > 2.0.CO;2.

- C. S. Bouchard, R. W. Przybylinski, R. J. Trapp, and G. Schmocker, 2005: Damaging surface wind mechanisms within the 10 June 2003 Saint Louis bow echo during BAMEX. Mon. Wea. Rev., 133, 2275-2296, https://doi.org/10.1175/ MWR2973.1.

Beck, J., and C. Weiss, 2013: An assessment of low-level baroclinity and vorticity within a simulated supercell. Mon. Wea. Rev., 141, 649-669, https://doi.org/10.1175/MWR-D-11-00115.1.

Benjamin, S. G., and Coauthors, 2016: A North American hourly assimilation and model forecast cycle: The Rapid Refresh. Mon. Wea. Rev., 144, 1669-1694, https://doi.org/10.1175/ MWR-D-15-0242.1.

Bolton, D., 1980: The computation of equivalent potential temperature. Mon. Wea. Rev., 108, 1046-1053, https://doi.org/ 10.1175/1520-0493(1980)108<1046:TCOEPT > 2.0.CO;2.

Bryan, G. H., and M. D. Parker, 2010: Observations of a squall line and its near environment using high-frequency rawinsonde launches during VORTEX2. Mon. Wea. Rev., 138, 4076-4097, https://doi.org/10.1175/2010MWR3359.1.
Conrad, D., and K. Knupp, 2019: Doppler radar observations of horizontal shearing instability in quasi-linear convective systems. Mon. Wea. Rev., 147, 1297-1318, https://doi.org/10.1175/ MWR-D-18-0257.1.

Dahl, J. M., 2015: Near-ground rotation in simulated supercells: On the robustness of the baroclinic mechanism. Mon. Wea. Rev., 143, 4929-4942, https://doi.org/10.1175/MWR-D-15-0115.1.

_, M. D. Parker, and L. J. Wicker, 2014: Imported and stormgenerated near-ground vertical vorticity in a simulated supercell. J. Atmos. Sci., 71, 3027-3051, https://doi.org/10.1175/ JAS-D-13-0123.1.

Davies-Jones, R. P., 1982: Observational and theoretical aspects of tornadogenesis. Intense Atmospheric Vortices, L. Bengtsson and J. Lighthill, Eds., Springer, 175-189.

Davies-Jones, R., and H. E. Brooks, 1993: Mesocyclogenesis from a theoretical perspective. The Tornado: Its Structure, Dynamics, Prediction and Hazards, Geophys. Monogr., Vol. 79, Amer. Geophys. Union, 105-114.

Davis, J. M., and M. D. Parker, 2014: Radar climatology of tornadic and nontornadic vortices in high-shear, low-CAPE environments in the mid-Atlantic and southeastern United States. Wea. Forecasting, 29, 828-853, https://doi.org/10.1175/WAFD-13-00127.1.

Dowell, D. C., and H. B. Bluestein, 1997: The Arcadia, Oklahoma, storm of 17 May 1981: Analysis of a supercell during tornadogenesis. Mon. Wea. Rev., 125, 2562-2582, https://doi.org/ 10.1175/1520-0493(1997)125<2562:TAOSOM>2.0.CO;2.

Engerer, N. A., D. J. Stensrud, and M. C. Coniglio, 2008: Surface characteristics of observed cold pools. Mon. Wea. Rev., 136, 4839-4849, https://doi.org/10.1175/2008MWR2528.1.

Flournoy, M. D., and M. C. Coniglio, 2019: Origins of vorticity in a simulated tornadic mesovortex observed during PECAN on 6 July 2015. Mon. Wea. Rev., 147, 107-134, https://doi.org/ 10.1175/MWR-D-18-0221.1.

Grzych, M. L., B. D. Lee, and C. A. Finley, 2007: Thermodynamic analysis of supercell rear-flank downdrafts from project ANSWERS. Mon. Wea. Rev., 135, 240-246, https://doi.org/ 10.1175/MWR3288.1.

Helmus, J. J., and S. M. Collis, 2016: The Python ARM Radar Toolkit (Py-ART), a library for working with weather radar data in the Python programming language. J. Open Res. Software, 4, e25, https://doi.org/10.5334/jors.119.

Hirth, B. D., J. L. Schroeder, and C. C. Weiss, 2008: Surface analysis of the rear-flank downdraft outflow in two tornadic supercells. Mon. Wea. Rev., 136, 2344-2363, https://doi.org/ 10.1175/2007MWR2285.1.

Hitchcock, S. M., R. S. Schumacher, G. R. Herman, M. C. Coniglio, M. D. Parker, and C. L. Ziegler, 2019: Evolution of pre- and postconvective environmental profiles from mesoscale convective systems during PECAN. Mon. Wea. Rev., 147, 23292354, https://doi.org/10.1175/MWR-D-18-0231.1.

James, R. P., P. M. Markowski, and J. M. Fritsch, 2006: Bow echo sensitivity to ambient moisture and cold pool strength. Mon. Wea. Rev., 134, 950-964, https://doi.org/10.1175/MWR3109.1.

King, J. R., M. D. Parker, K. D. Sherburn, and G. M. Lackmann, 2017: Rapid evolution of cool season, low-CAPE severe thunderstorm environments. Wea. Forecasting, 32, 763-779, https://doi.org/10.1175/WAF-D-16-0141.1.

Klemp, J. B., and R. Rotunno, 1983: A study of the tornadic region within a supercell thunderstorm. J. Atmos. Sci., 40, 359-377, https:// doi.org/10.1175/1520-0469(1983)040<0359:ASOTTR>2.0.CO;2.

Markowski, P. M., 2016: An idealized numerical simulation investigation of the effects of surface drag on the development 
of near-surface vertical vorticity in supercell thunderstorms. J. Atmos. Sci., 73, 4349-4385, https://doi.org/10.1175/JAS-D16-0150.1.

—, and Y. P. Richardson, 2009: Tornadogenesis: Our current understanding, forecasting considerations, and questions to guide future research. Atmos. Res., 93, 3-10, https://doi.org/ 10.1016/j.atmosres.2008.09.015.

- and -2014 : The influence of environmental low-level shear and cold pools on tornadogenesis: Insights from idealized simulations. J. Atmos. Sci., 71, 243-275, https://doi.org/ 10.1175/JAS-D-13-0159.1.

— , E. N. Rasmussen, J. M. Straka, and D. C. Dowell, 1998: Observations of low-level baroclinity generated by anvil shadows. Mon. Wea. Rev., 126, 2942-2958, https://doi.org/ 10.1175/1520-0493(1998)126<2942:OOLLBG > 2.0.CO;2.

—, J. M. Straka, and E. N. Rasmussen, 2002: Direct surface thermodynamic observations within the rear-flank downdrafts of nontornadic and tornadic supercells. Mon. Wea. Rev., 130, 1692-1721, https://doi.org/10.1175/1520-0493(2002)130<1692: DSTOWT $>2.0 . \mathrm{CO} ; 2$.

— , and Coauthors, 2012: The pretornadic phase of the Goshen County, Wyoming, supercell of 5 June 2009 intercepted by VORTEX2. Part II: Intensification of low-level rotation. Mon. Wea. Rev., 140, 2916-2938, https://doi.org/10.1175/MWR-D11-00337.1.

May, R., S. Arms, J. Leeman, and J. Chastang, 2017: Siphon: A collection of python utilities for accessing remote atmospheric and oceanic datasets. Unidata, accessed 24 February 2020, https://doi.org/10.5065/D6CN72NW.

,,-- P. Marsh, E. Bruning, J. R. Leeman, K. Goebbert, J. E. Thielen, and Z. S. Bruick, 2020: MetPy: A Python package for meteorological data. Unidata, accessed 21 May 2020, https:// doi.org/10.5065/D6WW7G29.

Met Office, 2015: Cartopy: A cartographic python library with a Matplotlib interface. Met Office, accessed 21 May 2020, https://scitools.org.uk/cartopy/docs/latest/.

Parker, M. D., B. S. Borchardt, R. L. Miller, and C. L. Ziegler, 2020: Simulated evolution and severe wind production by the 25 26 June 2015 nocturnal MCS from PECAN. Mon. Wea. Rev., 148, 183-209, https://doi.org/10.1175/MWR-D-19-0072.1.

Roberts, B., M. Xue, A. D. Schenkman, I. Dawson, and T. Daniel, 2016: The role of surface drag in tornadogenesis within an idealized supercell simulation. J. Atmos. Sci., 73, 3371-3395, https://doi.org/10.1175/JAS-D-15-0332.1.

Rotunno, R., and J. Klemp, 1985: On the rotation and propagation of simulated supercell thunderstorms. J. Atmos. Sci., 42, 271-292, https://doi.org/10.1175/1520-0469(1985)042<0271: OTRAPO $>2.0 . \mathrm{CO} ; 2$.

_ J. B. Klemp, and M. L. Weisman, 1988: A theory for strong, longlived squall lines. J. Atmos. Sci., 45, 463-485, https://doi.org/ 10.1175/1520-0469(1988)045<0463:ATFSLL>2.0.CO;2.

Schenkman, A. D., M. Xue, and M. Hu, 2014: Tornadogenesis in a high-resolution simulation of the 8 May 2003 Oklahoma City supercell. J. Atmos. Sci., 71, 130-154, https://doi.org/10.1175/ JAS-D-13-073.1.

Shabbott, C. J., and P. M. Markowski, 2006: Surface in situ observations within the outflow of forward-flank downdrafts of supercell thunderstorms. Mon. Wea. Rev., 134, 1422-1441, https://doi.org/10.1175/MWR3131.1.
Sherburn, K. D., and M. D. Parker, 2014: Climatology and ingredients of significant severe convection in high-shear, lowCAPE environments. Wea. Forecasting, 29, 854-877, https:// doi.org/10.1175/WAF-D-13-00041.1.

- and - 2019: The development of severe vortices within simulated high-shear, low-CAPE convection. Mon. Wea. Rev., 147, 2189-2216, https://doi.org/10.1175/MWR-D-18-0246.1.

Skinner, P. S., C. C. Weiss, J. L. Schroeder, L. J. Wicker, and M. I. Biggerstaff, 2011: Observations of the surface boundary structure within the 23 May 2007 Perryton, Texas, supercell. Mon. Wea. Rev., 139, 3730-3749, https://doi.org/10.1175/ MWR-D-10-05078.1.

Smull, B. F., and R. A. Houze, 1987: Rear inflow in squall lines with trailing stratiform precipitation. Mon. Wea. Rev., 115, 28692889, https://doi.org/10.1175/1520-0493(1987)115<2869: RIISLW $>2.0 . \mathrm{CO} ; 2$.

Thompson, R. L., B. T. Smith, J. S. Grams, A. R. Dean, and C. Broyles, 2012: Convective modes for significant severe thunderstorms in the contiguous United States. Part II: Supercell and QLCS tornado environments. Wea. Forecasting, 27, 1136-1154, https://doi.org/10.1175/WAF-D-11-00116.1.

Trapp, R. J., and M. L. Weisman, 2003: Low-level mesovortices within squall lines and bow echoes. Part II: Their genesis and implications. Mon. Wea. Rev., 131, 2804-2823, https://doi.org/ 10.1175/1520-0493(2003)131<2804:LMWSLA > 2.0.CO;2.

— S. A. Tessendorf, E. S. Godfrey, and H. E. Brooks, 2005: Tornadoes from squall lines and bow echoes. Part I: Climatological distribution. Wea. Forecasting, 20, 23-34, https://doi.org/10.1175/WAF-835.1.

Wakimoto, R. M., H. V. Murphey, C. A. Davis, and N. T. Atkins, 2006: High winds generated by bow echoes. Part II: The relationship between the mesovortices and damaging straightline winds. Mon. Wea. Rev., 134, 2813-2829, https://doi.org/ 10.1175/MWR3216.1.

Weisman, M. L., and C. A. Davis, 1998: Mechanisms for the generation of mesoscale vortices within quasi-linear convective systems. J. Atmos. Sci., 55, 2603-2622, https://doi.org/10.1175/ 1520-0469(1998)055<2603:MFTGOM>2.0.CO;2.

__, and R. J. Trapp, 2003: Low-level mesovortices within squall lines and bow echoes. Part I: Overview and dependence on environmental shear. Mon. Wea. Rev., 131, 2779-2803, https://doi.org/10.1175/1520-0493(2003)131<2779: LMWSLA $>2.0$. CO;2.

Weiss, C. C., and J. L. Schroeder, 2008: StickNet: A new portable, rapidly deployable, surface observing system. Bull. Amer. Meteor. Soc., 89, 1502-1503, https://doi.org/10.1175/15200477-89.10.1469.

, D. C. Dowell, J. L. Schroeder, P. S. Skinner, A. E. Reinhart, P. M. Markowski, and Y. P. Richardson, 2015: A comparison of near-surface buoyancy and baroclinity across three VORTEX2 supercell intercepts. Mon. Wea. Rev., 143, 2736-2753, https://doi.org/10.1175/MWR-D-14-00307.1.

Wheatley, D. M., and R. J. Trapp, 2008: The effect of mesoscale heterogeneity on the genesis and structure of mesovortices within quasi-linear convective systems. Mon. Wea. Rev., 136, 4220-4241, https://doi.org/10.1175/2008MWR2294.1.

$\mathrm{Xu}, \mathrm{X}$., M. Xue, and Y. Wang, 2015: The genesis of mesovortices within a real-data simulation of a bow echo system. J. Atmos. Sci., 72, 1963-1986, https://doi.org/10.1175/JAS-D-14-0209.1. 